\title{
Argentinos y peruanos en la ciudad de México, 1970-2009 ¿Configuración de una Ciudadania Transnacional Digital?*
}

\author{
Argentinians and Peruvians in Mexico City, 1970-2009. \\ Setting of a Transnational Digital Citizenship?
}

Argentinos e peruanos na cidade de México, 1970-2009. ¿Configuração de uma Cidadania Transnacional Digital?

Recibido el 27 de abril de 2014, aceptado el 5 de junio de 2014

Joselito Fernández Tapia**

Perú

\section{Resumen}

Objetivo: sistematizar y explicar la relación entre TIC y ciudadanía, principalmente a partir del Internet. Metodología: se aplica un método cualitativo, basado en las entrevistas a profundidad, la observación participante y el análisis de contenido de las páginas web. El estudio responde a un enfoque transnacional e intercultural de la integración y la ciudadanía. Resultados: se evidencia un transnacionalismo de Estado, así como de redes transnacionales crecientes a través de las nuevas Tecnologías de la información y comunicación (TIC). Éstas, vinculan redes directas en las que se realizan prácticas sociales que reproducen y reconfiguran relaciones,

\footnotetext{
* El presente artículo aborda la relación de la Migración internacional y la ciudadanía transnacional digital. Es parte de un estudio más amplio que inició al desarrollar la tesis doctoral para conocer cómo en la Ciudad de México se construye la ciudadanía de peruanos y argentinos en el periodo 1970-2009. Terminado el estudio, se continúa hasta la fecha en otro proyecto trabajando con detalle la relación TIC -ciudadanía en el caso de los peruanos y argentinos, un hecho que aún preocupa en una segunda etapa (2010-2014). El resultado de la primera fase, relacionada al vínculo TIC, migración y ciudadanía, es el presente documento.

** Doctor en Ciencias Sociales, con especialidad en Estudios Regionales, Profesor Investigador de la División de Estudios de Posgrado de la Universidad de la Sierra Sur. Oaxaca. México. Correo electrónico: joseft100 hotmail.com
} 
identidades y formas de percibirse y realizarse como ciudadanos, respecto a su país de origen y de destino. Estas redes y transnacioalismo forman espacios transnacionales en los que realizan prácticas y derechos ciudadanos, que van desde los civiles y económicos hasta los identitarios y políticos. Con el paso del tiempo, se perciben en su mayoría, como ciudadanos respecto de su país de origen y de la Ciudad de México. Conclusiones: se concluye que existe la formación de ciudadanías transnacionales, la reinvención y reproducción del Estado-nación en el espacio de los flujos y de los lugares y la emergencia de la Ciudadanía Transnacional Digital.

Palabras clave: Migración internacional, Ciudadanía transnacional, Integración, Ciudadanía Transnacional Digital.

\section{Abstract}

Objective: to systematize and explain the relationship between Information and Communication Technologies -ICT and citizenship, mainly from the Internet. Methodology: a qualitative method, based on in-depth interviews, participant observation and content analysis of websites is used. The study responds to a transnational and intercultural approach to integration and citizenship. Results: state transnationalism and growing transnational networks through ICT are evidenced. They connect direct networks in which social practices that reproduce and reconfigure relations, identities and ways of perceiving and performing as citizens regarding their country of origin and destination are performed. These networks and transnationalism make transnational spaces engaged in practices and citizen rights, ranging from civil and economic to political and identity rights. Over time, they are perceived mostly as citizens regarding their home country and Mexico City. Conclusions: the formation of transnational citizenship, the reinvention and reproduction of the State-Nation in the space of flows and places and the emergence of Transnational Citizenship Digital is a fact.

Keywords: International migration, Transnational Citizenship, Integration, Transnational Citizenship Digital.

\section{Resumo}

Objetivo: sistematizar e explicar a relação entreTecnologias da Informação e Comunicação -TIC- e cidadania, principalmente a partir da Internet. Metodologia: aplica se um método qualitativo, baseado nas entrevistas a profundidade, a observação participante e o analise de conteúdo das paginas web. O estudo responde a um enfoque transnacional e intercultural da integração e a cidadania. Resultados: evidencia se um transnacionalismo de Estado, assim como de redes transnacionais crescentes através das TIC. Estas vinculam redes diretas nas que se realizam praticas sociais que reproduzem e re configuram relações, identidades e formas de percebesse e realizar se como cidadãos, 
respeito ao seu país de origem e de destino. Estas redes e transnacionalismo formam espaços transnacionais nos que realizam praticas e direitos cidadãos, que vão desde os civis e econômicos até os identitária e políticos. Com o passo do tempo, se percebem em sua maioria, como cidadãos respeito de seu país de origem e da Cidade de México. Conclusões: conclui se que existe a formação de cidadanias transnacionais, a reinvenção e reprodução e reprodução do Estado - nação no espaço de fluxos e dos lugares e a emergência da Cidadania Transnacional Digital.

Palavras chave: Migração internacional, Cidadania transnacional, Integração, Cidadania Transnacional Digital. 


\section{Introducción}

En las últimas tres décadas, las migraciones internacionales han generado cambios sociales, económicos, políticos y culturales en los países receptores y emisores. Se ha convertido en un fenómeno trascendental y, potencialmente, beneficioso para países, regiones y el mundo. Sin embargo, también son "percibidas como un trastorno al orden económico internacional por la mayor parte de los países receptores” (Hiernaux y Zárate, 2008, p. 9), por lo que desarrollan políticas restrictivas y de control (López, 2002), que no han logrado parar su crecimiento.

Estas migraciones y los cambios derivados de los tratados de integración económica y política ${ }^{1}$ y las TIC, cuestionan, en la teoría y en la práctica, a la ciudadanía nacional y ejercen presión para expandir el contenido formal de esos derechos (extensión) y la ampliación de las categorías de individuos que los ejerzan, entre ellos a los inmigrantes.

Así, la migración internacional cuestiona a los tres elementos básicos de la ciudadanía nacional: territorio (límites físicos), identidad (la comunidad términos de identificación y afiliación cultural) y derechos (el perímetro de la ciudadanía y de la pertenencia definida como la asignación de derechos liberales) (López, 2002). Esto da lugar a las tensiones entre ciudadanía y territorio, ciudadanía y derechos y ciudadanía e identidad (Fernández, 2010), lo que trasciende a la ciudadanía del Estado-nación. El resultado es la formación de espacios, identidades y derechos transnacionales. Estos desajustes suceden también en los espacios de las TIC, porque en ellos también se construyen relaciones y espacios transnacionales.

\section{Antecedentes y aproximación a los casos de los inmigrantes de Perú y Argentina}

En el mundo y en algunos países de América Latina, están los estudios articulados a la dimensión política y de ciudadanía de la migración, políticas e instituciones de emigración y vinculación (Calderón, 2003b; Gamlen, 2006; Moraes, 2008; Vono de Villena, 2006), que muestran el transnacionalismo de Estado para integrar sus emigrados. Estudios más recientes (Lafleur, 2013; Padilla, 2011; Padilla y Ortiz, 2012; Gamlen, 2013) y el estudio de Ramírez (2013) sobre Ecuador, que plantea la ciudadanía universal basada en la justicia social. Los estudios de las TIC vinculados a los espacios transnacionales y ciudadanías imaginadas (Peñaranda, 2011; Feliú y Peñaranda, 2012), muestran hallazgos similares al presente estudio.

1. Tratados de libre comercio, Unión Europea, UNASUR, entre otros, y los diversos convenios internacionales y de derechos humanos. 
Respecto al Perú, los estudios de Luque (2002), Cerruti (2005), Stefoni (2004), tratan las relaciones transnacionales desde una perspectiva política y/o de ciudadanía; así como de Escrivá (2000) en España e Italia y Velazco (1998) en Italia, que destacan el rol central de las redes sociales y organizaciones de inmigrantes y la influencia de la cultura política de origen en las prácticas ciudadana ${ }^{2}$ y los que se refieren a la relación migración e identidad (Labrador, 2001). Sobre las TIC y ciudadanía, Retis (2011) en Brasil, resalta los vínculos entre las prácticas comunicacionales y la formación de las ciudadanías latinoamericana y cosmopolita.

En el caso argentino, están los estudios sobre la política emigratoria desde los años setenta a la actualidad (Novick, 1996; Calvelo, 2008), los estudios sobre los argentinos invisibles en Estados Unidos (con menores derechos o sin ellos), el asociacionismo y su rol e interconexión con el Estado y el establecimiento de instituciones estatales que gestionan la emigración (Calvelo, 2008; Novick et al, 2007). En relación con la ciudadanía, Pérez (2009) reflexiona sobre las políticas públicas nacionales e internacionales como fuente de ciudadanía en los países de origen y de destino. Garzón (2006) aborda la integración de argentinos y ecuatorianos en Barcelona y Milán y muestra la influencia de la cultura política de origen y la reproducción de estructuras sociales y políticas previas a la migración y los que tratan sobre el exilio, sus asociaciones y actividad política en México y España (Yankelevich, 2002; Yankelevich y Jensen, 2007). A excepción del exilio, entre argentinos y peruanos predominan las relaciones y prácticas relacionadas a los derechos civiles, económicos y culturales.

\section{De los modelos de análisis de las políticas de emigración y de vinculación}

\section{Gamlem (2006), clasifica las políticas en:}

capacity building policies, aimed at discursively producing a state-centric 'transnationalnational society', and developing a set of correspondingstateinstitutions; extending rights to the diaspora, thus playing a role that befits a legitimate sovereign, and extracting obligations from the diaspora, based on the premise that emigrants owe loyalty to this legitimate sovereign (Gamblen, 2006, pp. 5-6).

Levitt y de la Dehesa, (2003), clasifica las políticas de emigración en: 1) reformas ministeriales o consulares, 2) políticas para incentivar la inversión y el envío de remesas, 3) extensión de derechos políticos, 4) extensión de protección o servicios estatales e implementación de políticas simbólicas.

2. Encuentran, además, la centralidad de los espacios privados en las mujeres y con responsabilidades fundamentalmente domésticas y en muchos casos de subordinación a los hombres incluso a distancia, el predominio en el espacio público de los hombres y la prolongación de la subordinación doméstica. 
En el presente estudio, a partir del análisis de las políticas de Perú y Argentina, se plantea una tipología propia, de acuerdo con los objetivos y fines de la política migratoria:

Políticas de fortalecimiento del servicio público, que buscan la transformación del sistema institucional-administrativo bajo la premisa el modelo del servidor público en el marco de la modernización pública y las tendencias de la Nueva Gestión Pública. Se promueve un servicio consular eficiente, eficaz y de calidad. Para lograrlo, se crean oficinas específicas para realizar trámites, mejorar la relación gobierno-emigrantes y acercar los trámites: servicio consular itinerante, correo postal, entre otros.

Políticas de asistencia, que buscan suplir las necesidades básicas de alimentación, salud, seguridad, apoyo legal y repatriación en casos de emergencia y respeto a sus humanos.

Políticas de vinculación, que buscan integrar social, cultural y económicamente, a los emigrantes, involucrándolos en actividades socioculturales y productivas para el desarrollo de sus comunidades. Esto implica promover la integración y obligaciones con el país de origen.

Políticas de ciudadanización, son las dirigidas a la construcción y ejercicio de la ciudadanía en el exterior de sus comunidades de emigrantes que implica: el derecho al voto y ser elegido con respecto a su país de origen, la asistencia y ejercicio de todos sus derechos con el país de origen, hasta promover la integración y participación política en el país receptor.

\section{Migración internacional y TIC: hacia la ciudadania transnacional e intercultural}

La ciudadanía es entendida como un proceso de pertenencia a y participación en la comunidad $^{3}$, donde los individuos en diferentes grupos, clases y movimientos buscan mayores grados de autonomía y control sobre sus vidas y las decisiones públicas que

3. "Esta pertenencia y participación se realiza en una red de interacciones en la que se asumen compromisos cívicos y se ejercen derechos. Esta ciudadanía se expresa en cuatro dimensiones: a) Procedimental: conjunto de deberes y derechos reconocidos constitucionalmente y que determinan el status de ciudadano (los derechos civiles, políticos, sociales de Marshall (1948) y culturales (Taylor, 1993, 1997; Kymlicka, 2006). Incluye los status migratorios; b) Identitaria: pertenencia a una comunidad política o ético-cultural, en la que son iguales con respecto a dicha comunidad y diferentes con respecto a otra, en un proceso de inclusión/exclusión. Involucra afectos y lealtades con los que se considera iguales. En este caso, una identidad nacional o cultural. c) Simbólica: legitima los criterios nominales y/o identitarios de inclusión y exclusión que se producen en la comunidad nacional, en la cultura política y en el espacio público. Se realiza en imaginarios, símbolos, narrativas y rituales que justifican la norma establecida y que se asocia al nacionalismo, fuente cultural de la soberanía de la pertenencia y de igualdad en la comunidad política (Held, 1997). d) Sustantiva o participativa: Es el ejercicio de los deberes y derechos en prácticas ciudadanas concretas (Turner, 1993; Taylor 1988, citado en Habermas 1998, 626-627), el disfrute y acceso a ellos (Marshall, 1998)" (Fernández, 2010, p. 83). 
les afectan, frente a distintas formas de jerarquía, estratificación y opresión política (Held, 1997) y social ${ }^{4}$. Esta ciudadanía es dinámica y construida por los actores sociales y no solamente definidos por el Estado, a través de mediaciones culturales y tecnológicas, económicas, sociales y políticas. Sobre esta base, se plantean las siguientes dimensiones: ciudadanía reconocida (la legal, nominal), ciudadanía percibida (la identitaria-simbólica) y la ciudadanía vivida (ejercicio y disfrute de derechos y realización de deberes y compromisos cívicos), a través de las que se realiza la ciudadanía a nivel local, nacional y transnacional (Fernández, 2010).

La ciudadanía transnacional se define como el ejercicio de derechos y compromisos cívicos más allá del Estado-nación, que da lugar a comunidades que se mueven más allá de sus territorios (Baubock, 2003; Basch et al, 1994) y que penetran en otros donde realizan actividades y ejercen derechos. Esta ciudadanía se expresa en tres procesos: a) como prolongación del Estado-nación en su proceso de formación, reproducción y legitimación, extendiendo los derechos ciudadanos en el exterior en donde están, como por ejemplo el sufragio en el exterior; b) la pertenencia a dos comunidades, al adquirir la doble ciudadanía o ciudadanas múltiples, como mexicano-argentino o peruano-mexicano, a partir de la nacionalidad o de facto; y c) de un transnacionalismo supranacional, en el que se amplían o se adquieren derechos y compromisos en otros Estados como parte de una Unión de Estados o como un proyecto ideológico y político de integración regional o de ciudadanía universal $^{5}$.

El transnacionalismo, por su parte, corresponde a una serie de relaciones más allá de las fronteras nacionales de un país, ya sea solamente de uno hacia otro o relaciones mutuas, de regular intensidad; éstas, conforman espacios transnacionales en red que interconectan colectividades de origen y destino (Goldring, 1997), donde existe un intercambio de bienes e información social, cultural y cívica, basados en la nacionalidad, la amistad, el parentesco y la confianza (Enríquez, 2000). En estos espacios transnacionales se reconfigura de manera transformada la comunidad de origen en el país de destino (Riesco, 2003), que puede ser como asociación de intereses particulares, de comunidad en el sentido de identidad, solidaridad y reciprocidad (Tönnies, 1879) y/o comunidad imaginada (Anderson, 1993). Este es un aspecto central que se analiza en el presente estudio.

\footnotetext{
4. La ciudadanía no sólo implica lo político sino la vivencia de derechos involucra también la esfera social, que es donde se viven muchos de los derechos o donde no son respetados ni ejercidos.

5. Sobre estas formas de ciudadanía en el caso latinoamericano, existen comunidades como la de los dominicanos en Estados Unidos, ampliamente estudiada, sobre ciudadanía transnacional en el primer caso mencionado. En el segundo caso, los mexicanos con doble nacionalidad que ejercen sus derechos en sus dos países o en sus comunidades locales, son ejemplos concretos. En el tercer caso, la construcción de una comunidad imaginada de América Latina o la Unión Europea.
} 
En estas comunidades y redes transnacionales, directas o mediadas por la tecnología ${ }^{6}$, el componente identitario y simbólico es el que se fortalece (Levitt y De la Dehesa, 2003), se reproducen las estructuras sociales del país de origen (Smith,1995; Pries, 1999) y la nación de origen (Moraes, 2008), y la ciudadanía que se gesta tiende a incluir a los diferentes, su diversidad social y cultural (Kymlicka, 2006), tanto desde sus propias interacciones sociales en espacios transnacionales o desde las políticas de Estado, de origen o de destino. Consecuentemente, la ciudadanía se transnacionaliza y exige de los Estados, emisor y receptor, una integración política (Pajares, 2005), plena y efectiva. Surgen a la vez identidades traslapadas: latinoamericana (Retis, 2011), global o cosmopolita (Castles y Davidson, 2000) y de la ciudad (Borja, 2000). En ese proceso, los Estados se reproducen y recrean mediante las políticas de emigración y en los espacios sociales (directos o digitales) de los emigrantes.

Estas transformaciones e interacciones se construyen en el espacio de los flujos (electrónicos) (Castells, 1997), como nuevo espacio público (Innerarity, 2006) y el espacio de los lugares (Castells, 1997) o directos (este espacio es principalmente la ciudad y sus lugares físicos de encuentro). La ciudad, por lo tanto, es un espacio público integrado al privado, un lugar de intercambio (urbs), de participación en lo público (civitas) y en política (polis) (Borja, 2000). En consecuencia, ciudad e internet son espacios de circulación e intercambio y espacios políticos, públicos y privados, en los que la ciudadanía se realiza y se transforma.

El uso de las TIC y la participación en el espacio de los flujos generan un tipo de membresía simultánea entre dos comunidades que hacen que su participación sea totalmente distinta (Peñaranda, 2011) y una ubicación como en un plano supraterritorial (Escriba y Rivas, 2004, citado en Peñaranda, 2011). Así, Las TIC "son una expresión, y, a la vez una forma de construcción de las formas de hacer y decir las relaciones y los afectos en la sociedad contemporánea" (Peñaranda, 2011a) y se articula a la comprensión de los procesos migratorios transnacionales (Peñaranda et al, 2011b) y de la ciudadanía.

Los migrantes territoriales evolucionan más rápido a migrantes digitales por la necesidad de comunicación, lo que se hace por vía móvil e internet, cuyo uso es alto entre ellos con prácticas comunicativas que influyen en el desarrollo de la ciudadanía intercultural de los emigrados (Retis, 2011). Los contenidos mediáticos pueden afectar la formación identitaria simbólica como sucede en la construcción de la identidad latinoamericana de los peruanos a partir de estrategias mediáticas de la Asociación CIBAI-Migraciones en Brasil (Gogo y Dutra, 2009). Las TIC también forman espacios transnacionales y múltiples comunidades imaginadas como en locutorios y en las redes sociales que se generan en la conexión de las TIC en España

6. Se denomina redes directas a las que realiza en el espacio de los lugares y redes mediadas por las tecnologías a las que se realizan en la internet y a través de la telefonía fija o móvil. 
(Feliú y Peñaranda, 2012). Así, se construye la transnacionalidad en los espacios telemáticos como en el de los lugares, en los que se realiza la reconfiguración socialsimbólica de su ciudadanía, que trasciende a la ciudadanía nacional. Ciudadanía a la cual Brubaker lo plantea como una discusión sobre la nacionalidad, sobre lo que significa y lo que es pertenecer a un Estado-nación como realidad institucional, social, psicológica y política. Como una manera de organizar y experimentar la calidad de miembro político y social de una comunidad concreta, que incluye a los nacionales y excluye a los extranjeros. Concepción ésta en la que la nación-Estado es igualitaria, sagrada, nacional, democrática, única y social ${ }^{7}$ (Brubaker, 1998). Esta es la que predomina y que es cuestionada por la migración internacional y las TIC.

A esta tesis, se le antepone la ciudadanía como una cuestión de derechos y de discusión sobre los derechos, la que es incluyente. De una parte, remite a "aquel estatus que se concede a los miembros de pleno derecho de una comunidad", cuyos "beneficiarios son iguales en cuanto a derechos y obligaciones..." (Marshall y Bottomore, 1998: 37), que hace referencia a su carácter formal. De otra parte, la ciudadanía es un conjunto de prácticas jurídicas, políticas, económicas y culturales que definen a una persona competente en su sociedad y que son el resultado del flujo de recursos a los individuos y a los grupos sociales (Turner, 1993). La ciudadanía, entonces, no sólo es un estatus jurídico de reconocimiento, extensión y ampliación de derechos y responsabilidades formales, sino un proceso de interacción social donde "su crecimiento es estimulado, tanto por lucha para ganar esos derechos, como por su disfrute" (Marshall y Bottomore, 1998, p. 24). Esto implica la pertenencia a una comunidad política como hombres libres y cuyos derechos son protegidos por una ley común, en la que tienen responsabilidades con la comunidad (Marshall y Bottomore, 1998). Esto convierte al individuo en sujeto de derechos, los que pueden emanar de diferentes fuentes de legitimidad: nacionalidad-Estado, residenciaciudad, derechos humanos-mundo.

En esta triple relación se visibiliza la multiculturalidad y se construye la interculturalidad, lo que la teoría del interculturalismo y el multiculturalismo busca comprender y normar, que aunque tienen similitudes, sus diferencias son sustanciales y se sintetizan a continuación:

7. Esta igualdad, sin embargo, fue excluyente porque como valor cívico, desde la Revolución Francesa, fue desigual genérica y etnocultural. En relación con el género, la igualdad heredada de las revoluciones burguesas privilegió a los varones y excluyó a la mujer. Etnoculturalmente, favoreció a los blancos en desmedro de los negros y los indígenas. En relación a la nación, incluye a los nacionales y excluye a los extranjeros, los inmigrantes. 
Fernández Tapia, Joselito (2014). Argentinos y peruanos en la ciudad de México, 1970-2009. ¿Configuración de una Ciudadanía Transnacional Digital? Ánfora, 21(36), 91-123. Universidad Autónoma de Manizales. ISSN 0121-6538.

Cuadro 1. Diferencia entre el culturalismo multicultural y el interculturalismo ciudadano

\begin{tabular}{|c|c|}
\hline Multiculturalismo culturalista & Interculturalismo ciudadano \\
\hline $\begin{array}{l}\text {, Hincapié en la diferencia y su } \\
\text { reconocimiento. } \\
\text {, Relaciones entre culturas } \\
\text {, Promoción de colectivos etnoculturales } \\
\text {, Culturalismo esencialista } \\
\text {, Se fundamente en la diversidad cultural } \\
\text {, Promueve ciudadanías diferenciadas y la } \\
\text { frontera nosotros/ellos. } \\
\text {, Promueve políticas específicas para } \\
\text { inmigrantes } \\
\text {, Favorece la segregación y acciones } \\
\text { deparadas. } \\
\text {, La integración es como agregación para } \\
\text { ser parte de la comunidad política por } \\
\text { yuxtaposición. } \\
\text {, Su ciudadanía es la "ciudadanía multicultural" }\end{array}$ & $\begin{array}{l}\text {, Hincapié en la igualdad en la diversidad y } \\
\text { pluralismo democrático. } \\
\text {, Construcción de proyectos comunes. } \\
\text {, Promoción de proyectos ciudadanos. } \\
\text {, Identidades dinámicas y múltiples. Pluralismo } \\
\text { democrático. } \\
\text {, Se fundamenta en la libertad cultural. } \\
\text {, Promueve ciudadanía cohesionada y el } \\
\text { pluralismo cosmopolita. } \\
\text {, Promueve políticas públicas universalista } \\
\text { que incluye a los inmigrantes } \\
\text {, Favorece la formación de una identidad } \\
\text { compartida. } \\
\text {, La integración es de ciudadanía en la } \\
\text { comunidad política. } \\
\text {, Su ciudadanía es la "ciudadanía intercultural” }\end{array}$ \\
\hline
\end{tabular}

Fuente: Elaboración propia a partir de Castellas y Rocha (2009, p. 15) y Bilbeny (2007). La clasificación original es de Castellas y Rocha, a la que se le incorporan elementos retomados de Bilbeny $(2002,2007,2008)$ para darle mayor claridad (citado por Fernández, 2010, p. 108).

Los planteamientos de Bilbeny (2004, 2002), Borja (2004) y Cortina (1998) coinciden con los de Kymlicka (1996) y Taylor (1993) en los siguientes aspectos: a) el reconocimiento de la diversidad cultural y de sus derechos por el sector mayoritario de la comunidad; b) la necesidad de una identidad ciudadana compartida para fortalecer la unidad y cohesión social de la comunidad política; c) la incorporación de los derechos humanos; d) la participación de los inmigrantes; y e) la importancia de los factores socioculturales en la ciudadanía.

Esta postura permite una ciudadanía incluyente en la que las identidades culturales y diversidad social y cultural se realicen como derechos y libertades y sea posible la integración de los inmigrantes a la comunidad política (Pajares, 2005); superar la posición nacionalista de que "el reconocimiento de derechos a la población extranjera supondría una ruptura de la identidad nacional y del patriotismo" (Solanes, 2008, p.73) y que los inmigrantes internacionales son un peligro para la democracia y unidad nacional (Pickus,1998). Reafirma, en cambio, que son elementos enriquecedores de la cultura nacional y democracia (Kymlicka, 2003), en la que la integración intercultural produciría una ciudadanía compartida, 
intercultural y participativa (Bilbeny, 2002, 2007), que garantice el reconocimiento de la identidad de los actores y la igualdad de sus derechos con los nacionales.

En la relación migración internacional, TIC y ciudadanía, existe una reinvención de la identidad nacional y la construcción de espacios transnacionales, en los que con prácticas concretas centradas en la nacionalidad, reinventan comunidades imaginadas (Peñaranda, 2011; Gogo y Dutra, 2009), en que el que se reproduce la nación más allá del territorio nacional (Moraes, 2008). Esto contradice la tesis de debilitamiento del Estado-nación debido a la crisis del Estado y la emergencia de lo local (Appadurai, 1999), pues "la falta de credibilidad en el Estado y en el sistema político no conduce directamente al declive a la nación (Grimson, 2004). Además los Estados se reinventan mediante políticas migratorias (Gamlen, 2006; Padilla, 2011; Lafleur; 2013) y en las relaciones entre inmigrantes, porque a la ausencia de la "familia y amigos lejanos [...] los paisanos o connacionales $s^{8} n^{8}$ fuentes primarias de comunidad e identificación (Miller, 1997). Relaciones, en las que los reinventan y mitifican sus historias para reestructurar sus identidades actuales (Pérez, 1991), como su comunidad en el país receptor.

\section{El problema: ¿existe una ciudadanía transnacional digital?}

Hasta 1998 no son grandes las diferencias entre mexicanos y extranjeros en el ejercicio de derechos en la Ciudad de México porque no tenían derechos políticos reconocidos. Después de esta fecha y, sobre todo desde el 2000, los extranjeros quedan excluidos del voto, de los comités ciudadanos de representación y por la prohibición constitucional de no participar ni opinar en los asuntos públicos de México. La única vía para ejercer derechos políticos, excluyendo el de ser elegidos, es adquirir la nacionalidad mexicana, cuya realización exige la renuncia a la nacionalidad de origen. Todo esto puede ser en un obstáculo importante para la realización ciudadana de peruanos y argentinos que viven en la Ciudad de México.

Antes de 1990, los ciudadanos argentinos y peruanos, no podían mantener información permanente con el país de origen ni participar activamente en relaciones familiares ni en procesos socioculturales, económicos o políticos. Lo más que podía hacerse es vivir entre recuerdos y nostalgias o producir una escisión y continuar su vida en México. Con la telefonía, entre 1970-2000, la comunicación era posible pero de acceso difícil, lo que hacía difícil pensar siquiera en una ciudadanía transnacional. Sin embargo, los argentinos, entre 1970-1983, vivieron un activo transnacionalismo político desde los ciudadanos que estaban contra la dictadura y recibieron el apoyo del pueblo y gobierno mexicanos, pero al disolverse la dictadura, tanto sus redes, como sus asociaciones y acción política transnacional terminó.

8. La cursiva es propia y reemplazan a "como". 
A partir de los años noventa, al caer los socialismos reales y surgir la globalización económica homogenizante, se demarcan nuevos rumbos en los que se disolvieron la formas de organización y participación política en relación al país de origen tanto entre peruanos como argentinos en la Ciudad de México, en el que la participación política parecía que no iba a resurgir más allá del ejercicio del voto en las elecciones presidenciales. Sin embargo, la emergencia de las nuevas TIC (TV, radio, telefonía celular e internet) da lugar al surgimiento de redes electrónicas o telemáticas, en los que peruanos y argentinos participan desde el ejercicio del derecho al ocio hasta posible realización de derechos económicos, políticos y culturales.

Hi5, yahoo, facebook, you tobe, son espacios en los que comienzan a utilizar y en los que se conectan con otros peruanos y argentinos en la ciudad, con su país de origen y el mundo.

La posibilidad de conformación y extensión 1) comunidades basadas en la vecindad, la cercanía, la confianza, el interés común y la solidaridad o 2) asociaciones basadas en un marcador de identidad y regidas por intereses particulares (Tönnies, 1979), como el equivalente al grupo secundario de Cooley (2003) y en esa perspectiva conocer cómo influyen o no en las "comunidades imaginarias", como la nación de Anderson (1993), lo cual es importante para el debate actual sobre la ciudadanía, pero sobre todo para saber si en la práctica se realizan, o tal vez constatar que el Estado nación y la ciudadanía nacional están en declive o se debilitan como sostiene Castells (2004) y (Appadurai, 1999).

En este contexto teórico se analiza la relación entre TIC en la ciudadanía de peruanos y argentinos en la Ciudad de México para el periodo 1970-1989: la influencia en las diferentes dimensiones de la ciudadanía, si se transforman o solo se transforman sus medios de expresión, si se reproducen las identidades y ciudadanías de origen, son sustituidas por otras o son ampliadas. A la vez sobre su influencia en las relaciones entre ciudadanos y gobiernos,

\section{Metodología}

El estudio es cualitativo y compara dos casos: el de los argentinos y el de los peruanos que han vivido en la Ciudad de México en el periodo 1970-2009. Para cumplir tal fin, se utiliza la entrevista a profundidad, la observación participante y el análisis de contenido web. Es interpretativo porque busca descripciones profundas que permitan cuestionar, reinterpretar y confrontar las teorías existentes con los resultados de la investigación y aportar información innovadora. Asimismo, describe y explica la realidad buscando vínculos entre la condición del inmigrante peruano y/o argentino con su cultura e identidad, redes, integración y ciudadanía en el contexto particular de la Ciudad de México.

A partir de casos particulares se analiza los derechos y deberes de los peruanos 
y argentinos en relación a las TIC, desde la perspectiva de la ciudadanía, el transnacionalismo y el interculturalismo. Esta estrategia permite explicar el fenómeno y construir conocimiento mediante la particularización y explicación de casos en una perspectiva contextualizada. Al comparar la particularidad y complejidad de estos casos singulares, hace posible comprender el fenómeno en sus circunstancias más importantes (Stake, 1998), para especificar las convergencias como las divergencias y contrastarlas con la teoría.

Se hicieron entrevistas a profundidad con el fin de comprender sus visiones de la ciudadanía y ejercicio, y su relación con sus procesos de vida y migración expresadas a través de sus palabras (Taylor y Bogdan, 1992). Se aplica a 20 personas por país. Para seleccionar a los entrevistados se tuvo en cuenta que sean dirigentes que conocieran en detalle a la comunidad y activos en ellas como a quienes no lo eran, el tiempo de residencia mínimo de un año, el género y la generación, independientemente de si son residentes temporales o permanentes, aunque por el gran número de inmigrantes no fue posible representar a toda la pluralidad. Se utilizó entre los argentinos cuatro rondas de bola de nieve y entre Perú tres, con ayuda de internet y a partir del conocimiento de ciertas personas, organizaciones y el internet.

La observación se realizó en periodos cortos y paralelamente a las entrevistas. En algunos casos llegó a ser observador completo (Bufoord, 1960, en Álvarez-Gayou, 1998), como en sus fiestas, cenas, eventos particulares. Asimismo, la observación fue de carácter narrativo y cerrado (Rodríguez et tal, 1999, en Álvarez-Gayou), porque se buscó conocer detalladamente los espacios en que interactúan, registrando: a) interacciones, b) rutinas, c) rituales, d) organización social de los participantes, e) la organización del espacio, f) símbolos identitarios, g) patrones de comportamiento, h) temas de conversación, y i) elementos circunstanciales importantes.

La observación también se realizó en los restaurantes ${ }^{9}$, que seleccionaron de manera libre y otros por recomendaciones. Se buscó cubrir escenarios vinculados a diferentes grupos sociales, así como pequeñas fondas, medianos y grandes. También se observaron reuniones de mate ${ }^{10} \mathrm{y}$ conversaciones informales, como pláticas de café con los argentinos. Entre los peruanos se participó en las festividades tradicionales de cumpleaños; fiestas de fin de semana que realizaban los peruanos empleados

\footnotetext{
9. La observación se combinó entre semana y los fines de semana. Los restaurantes peruanos observados fueron: Astrid y Gastón en Polanco (Consorcio transnacional peruano), Máncora en Polanco (Franquicia peruana-mexicana), El Refugio del Inca (Restaurante familiar) y Las Nazarenas en la Delegación Cuauhtémoc (Restaurante familiar). Los restaurantes argentinos observados fueron Biela en Benito Juárez, El Rincón Argentino en Polanco, Cambalache en Polanco, El Sol Argentino en Benito Juárez y El 10 en La Condesa.

10. El mate es una infusión que se toma con un sorbete sólo o en reuniones. Como un evento colectivo "tomar mate" o una "mateada" es compartir el mate, lo que implica amistad, plática, comunidad de amigos. El mate se toma en un depósito común con el mismo sorbete, que se va rotando al tiempo que se platica. Es una tradición en Argentina, Uruguay, Paraguay y parte del Sur de Brasil.
} 
de empresas y trabajadoras domésticas, a los que asistían algunos profesionales y comerciantes; celebración del aniversario cívico de Perú, día de la canción criolla y la festividad del Señor de los Milagros.

El análisis de contenido se hizo a través del siguiente modelo:

Este modelo articula la teoría de ciudadanía con la transnacional. Para cada dimensión se elabora una serie de indicadores que hacen posible el análisis. Por razones de espacio en el artículo no se especifican, pero se pueden consultar en Fernández (2010).

Cuadro 1. Proceso de la experiencia ciudadana de los inmigrantes

\begin{tabular}{|c|c|c|c|}
\hline & $\begin{array}{c}\text { Ciudadanía } \\
\text { reconocida }\end{array}$ & $\begin{array}{c}\text { Ciudadanía } \\
\text { percibida }\end{array}$ & $\begin{array}{c}\text { Ciudadanía } \\
\text { Vivida }\end{array}$ \\
\hline Dimensión & Nominal o formal & Simbólica-cultural & Sustantiva/práctica \\
\hline Membresía & Jurídica & Identitaria & Social \\
\hline $\begin{array}{c}\text { Relación con el } \\
\text { territorio }\end{array}$ & $\begin{array}{c}\text { Local/nacional/ } \\
\text { global }\end{array}$ & $\begin{array}{c}\text { Local/nacional/ } \\
\text { global/ } \\
\text { transnacional }\end{array}$ & $\begin{array}{c}\text { Ejercicio de } \\
\text { deberes y } \\
\text { derechos/habitus }\end{array}$ \\
\hline Realización & Leyes/políticas & $\begin{array}{c}\text { Identidad/ } \\
\text { Símbolos/ } \\
\text { Imaginarios/ } \\
\text { narrativas }\end{array}$ & $\begin{array}{c}\text { Local/nacional/ } \\
\text { transnacional }\end{array}$ \\
& & \multicolumn{3}{|c}{} \\
\hline
\end{tabular}

Fuente: Elaboración propia (2010)

\section{Resultados}

\section{Redes sociales directas entre los peruanos y argentinos en Ciudad de México}

Estas redes se estructuran directamente en la acción pero tienen como soporte el teléfono, el correo electrónico o y el mensajero). Entre los peruanos se identificaron las siguientes: 
Cuadro 2. Redes directas de los peruanos

\begin{tabular}{|c|c|c|c|}
\hline Red & Descripción y actividades & $\begin{array}{l}\text { Resultados y vínculos } \\
\text { transnacionales }\end{array}$ & $\begin{array}{l}\text { Obtención de la } \\
\text { información }\end{array}$ \\
\hline $\begin{array}{l}\text { Red de co- } \\
\text { merciantes y } \\
\text { empresarios }\end{array}$ & $\begin{array}{l}\text { Organismo que busca garantizar las relacio- } \\
\text { nes comerciales y negocios entre Perú y Mé- } \\
\text { xico. Su comunicación principal es a través del } \\
\text { celular, teléfono y correo electrónico. }\end{array}$ & $\begin{array}{l}\text { Formación de la Cámara de comercio } \\
\text { mexicano-peruana. } \\
\text { Circuito económico transnacional Mé- } \\
\text { xico-Perú. }\end{array}$ & $\begin{array}{c}\text { Entrevista, Paula, } \\
\text { 2009. Análisis de } \\
\text { la web: } \\
\text { www.camaramexi- } \\
\text { canoperuana.com }\end{array}$ \\
\hline $\begin{array}{l}\text { Red de artesanos } \\
\text { y comerciantes } \\
\text { peruanos. }\end{array}$ & $\begin{array}{l}\text { Es un sector socioeconómico importante arti- } \\
\text { culado al mercado global de las artesanías con } \\
\text { China, Brasil y otros países. Su comunicación } \\
\text { principal es a través del celular, teléfono y co- } \\
\text { rreo electrónico. Dirigido por artesanos con } \\
\text { una economía estable y con influencia impor- } \\
\text { tante en la comunidad peruana del Df y en la } \\
\text { comunidad religiosa Señor de los milagros. }\end{array}$ & $\begin{array}{l}\text { Red productiva transnacional exitosa. } \\
\text { Sus dirigentes y miembros más im- } \\
\text { portantes tienen influencia entre los } \\
\text { comerciantes de artesanía del Distrito } \\
\text { Federal. } \\
\text { Influencia en las actividades culturales } \\
\text { y religiosas de la comunidad peruana } \\
\text { en el Distrito Federal. }\end{array}$ & Observación \\
\hline Red de Amalia ${ }^{11}$ & $\begin{array}{l}\text { Red de artesanía y medicina folklórica perua- } \\
\text { no-mexicano entre Cuzco- México en la que } \\
\text { la internet facilita los encuentros en vivo en } \\
\text { Cuzco para realizar ceremonias pre-incas en } \\
\text { honor a la tierra. Buscan difundir los valores } \\
\text { de la cultura prehispánica como estilo de vida } \\
\text { y de solución a los problemas personales y so- } \\
\text { ciales actuales. Su número es impreciso pero } \\
\text { sobrepasan el centenar. El soporte de comu- } \\
\text { nicación es el correo electrónico y la telefonía } \\
\text { fija y celular. }\end{array}$ & $\begin{array}{l}\text { Formación de una red transnacional } \\
\text { peruano-mexicana. } \\
\text { Comunidad transnacional en forma- } \\
\text { ción. } \\
\text { Encuentros en México y Perú. } \\
\text { Viajes de turismo cultural en México } \\
\text { y Perú. } \\
\text { Ejercicio de derechos culturales y de } \\
\text { organización. } \\
\text { Re de relación cara a cara en el sentido } \\
\text { de comunidad. }\end{array}$ & $\begin{array}{l}\text { Entrevista, Amalia, } \\
2009 .\end{array}$ \\
\hline Red de Walter ${ }^{12}$ & $\begin{array}{l}\text { Lo conforman sesenta trabajadores peruanos } \\
\text { que de empresas mexicanas, autoempleados, } \\
\text { como trabajadoras del hogar y algunos profe- } \\
\text { sionales. Esta red es de amistad y solidaridad. } \\
\text { Las reuniones son para compartir, celebrar } \\
\text { festividades, cumpleaños y sobrellevar el } \\
\text { extrañamiento. Este espacio es usado por } \\
\text { varios de ellos para comunicarse con el Perú } \\
\text { vía Internet y teléfono desde las casas de los } \\
\text { peruanos donde se reúnen en Azcapotzalco, } \\
\text { Delegación que se ubica al norte de la Ciudad } \\
\text { de México. Sus integrantes son de grupos so- } \\
\text { ciales escasos recursos de Perú y de diversas } \\
\text { regiones. }\end{array}$ & $\begin{array}{l}\text { Espacio transnacional donde se reali- } \\
\text { zan los derechos sociales y sirven de } \\
\text { soporte al extrañamiento, la nostalgia } \\
\text { y problemas de tipo social. } \\
\text { Red de relación cara a cara en el sen- } \\
\text { tido de asociación y grupo de interés. } \\
\text { Reproducen relaciones sociales y cos- } \\
\text { tumbres de Perú. }\end{array}$ & $\begin{array}{l}\text { Entrevista, Walter, } \\
2009 . \\
\text { Observación } \\
\text { participante, } \\
\text { 2008-2009. }\end{array}$ \\
\hline $\begin{array}{l}\text { Red de peruanos } \\
\text { en el sur de } \\
\text { México }\end{array}$ & $\begin{array}{l}\text { Lo conforman miembros de la comunidad pe- } \\
\text { ruana del Distrito Federal que llegaron desde } \\
\text { los años setenta hasta recién emigrados. El } \\
\text { objetivo es reunirse para confraternizar, ju- } \\
\text { gar fútbol rápido, compartir música y comida } \\
\text { peruana. Hasta los noventa se reunían per- } \\
\text { manentemente, pero en el presente siglo lo } \\
\text { hacen de vez en cuando. Sus integrantes son } \\
\text { principalmente de clase media. }\end{array}$ & $\begin{array}{l}\text { Es de confraternidad. Y cumple la fun- } \\
\text { ción de grupo de referencia primario, } \\
\text { son bastante conocidos y tienen un } \\
\text { sentido de comunidad, de amistad y } \\
\text { solidaridad. La mayoría de sus miem- } \\
\text { bros provienen de la zona metropoli- } \\
\text { tana peruana Lima-Callao. } \\
\text { Reproducen relaciones sociales y cos- } \\
\text { tumbres de Perú. Participan en ella } \\
\text { mexicanos y de otras naciones. }\end{array}$ & $\begin{array}{l}\text { Observación } \\
\text { participante. } \\
\text { Entrevista, Sr. } \\
\text { García, 2009. }\end{array}$ \\
\hline
\end{tabular}

Fuente: Elaboración propia (2010)

11. Trabajadora social peruana, nacionalizada mexicana e impulsora de una red basada en la cultura tradicional de México y Perú.

12. Trabajador de una empresa mexicana, vivía solo y con familia en Perú, con esposa e hijos en Perú comunicaba con frecuencia. 
Amalia, señala: "participo en el movimiento cultural tradicional, aquí, y promuevo los viajes espirituales a Machu Picchu y la realización de ofrendas a la tierra. Organizo los viajes que se hacen a Perú y viajamos cada año (...). Creo que las respuestas y soluciones a los problemas de hoy está volviendo a nuestras raíces, a la tradición de nuestros pueblos".

En estas redes se reproduce la cultura peruana a partir de elementos socioculturales peruanos y mexicanos, como sucede entre los peruanos que viven en Santiago de Chile que combinan elementos peruanos y chilenos (Luque, 2004) en la reconfiguración de identidades y prácticas. Todas estas redes, a excepción de la de Amalia son sociedades de grupo de interés.

Entre los argentinos, las redes sociales directas, no obstante su multiplicidad de redes que existen, por razones de tiempo se analizan aquellas que fue posible tener el acceso. Entre estas redes tenemos.

Cuadro 3. Redes directas de los argentinos

\begin{tabular}{|c|c|c|c|}
\hline Red & Descripción y actividades & $\begin{array}{l}\text { Resultados y vínculos } \\
\text { transnacionales }\end{array}$ & $\begin{array}{l}\text { Obtención de } \\
\text { la información }\end{array}$ \\
\hline $\begin{array}{l}\text { Red de } \\
\text { Lousiana }\end{array}$ & $\begin{array}{l}\text { Es una red articulada en torno a la Lousiana, quien } \\
\text { popularizó las cenas para argentinos y la red de } \\
\text { Alberto que organiza reuniones para tomar mate } \\
\text { y platicar. se organiza a partir de una red social } \\
\text { electrónica "Argentinos en la Ciudad de México } \\
\text { reúne entre } 20 \text { a } 60 \text { personas cada mes o cada } \\
\text { dos meses, en las festividades argentinas ( } 25 \text { de } \\
\text { mayo, día de la madre, día del amigo) o cuando } \\
\text { ellos acuerdan reunirse y compartir un almuerzo. } \\
\text { Confraternizan con comida argentina, juego de } \\
\text { cartas Ilamado "truco", música argentina y en la } \\
\text { que se conversa de temas cotidianos, o de políti- } \\
\text { ca y fútbol de Argentina, como sucede entre los } \\
\text { peruanos en sus reuniones que hablan de fútbol y } \\
\text { política peruana. }\end{array}$ & $\begin{array}{l}\text { Ejercicio del derecho de trabajo, aun- } \\
\text { que no tiene permiso, basado en los } \\
\text { vínculos de identidad, afectividad y } \\
\text { utilidad, no como sostiene Enríquez } \\
\text { (2000) que las redes de los inmigran- } \\
\text { tes se basan en relaciones de con- } \\
\text { fianza, reciprocidad y solidaridad. Las } \\
\text { necesidades que satisfacen son utilita- } \\
\text { rias y tienen un sentido práctico (Ong, } \\
\text { 1999), incluyendo las necesidades } \\
\text { afectivas y nostálgicas, que es similar } \\
\text { entre la mayoría de peruanos. }\end{array}$ & $\begin{array}{c}\text { Observación. } \\
\text { Entrevista, } \\
\text { Lousiana, 2009 } \\
\text { Entrevista, } \\
\text { Fatima, 2009 }\end{array}$ \\
\hline $\begin{array}{l}\text { Red de } \\
\text { Alberto }\end{array}$ & $\begin{array}{l}\text { La segunda a partir de la red social denominada } \\
\text { "Argentos". La de Alberto comparte mateadas (re- } \\
\text { uniones donde se platica y se toma mate, una hier- } \\
\text { ba en infusión tradicional de Uruguay y Argentina). } \\
\text { Germán (entrevista, Argentina, 2009) los describe } \\
\text { como: "espacios donde uno comparte con otros } \\
\text { los mismo códigos y se siente como en casa. El so- } \\
\text { porte tecnológico para estas redes son las redes } \\
\text { sociales electrónicas de yahoo y la comunicación } \\
\text { a través del celular. }\end{array}$ & $\begin{array}{l}\text { Red productiva transnacional exitosa. } \\
\text { Sus dirigentes y miembros más im- } \\
\text { portantes tienen influencia entre los } \\
\text { comerciantes de artesanía del Distrito } \\
\text { Federal. } \\
\text { Influencia en las actividades culturales } \\
\text { y religiosas de la comunidad peruana } \\
\text { en el Distrito Federal. }\end{array}$ & $\begin{array}{l}\text { Observación. } \\
\text { Entrevista, } \\
\text { Alberto, 2009. }\end{array}$ \\
\hline
\end{tabular}

Fuente: Elaboración propia (2010)

13. Argentina, bióloga, que al llegar a México y considerar que su salario como maestra en México no alcanzaba para sus gastos y era menor al que tenía en Argentina se dedicó a la gastronomía argentina y venta a domicilio y realización de reuniones donde vende comida y dulces, siendo muy conocida por los argentinos de la ciudad y de diferentes organizaciones argentinas. 
Fatima (entrevista, 2009), hace énfasis en el sentido utilitarista de la red: "no me gusta, la mayoría va por una cuestión de utilidad personal, no hay un sentido de pensar en el otro, con Lousiana, por ejemplo (al referirse a la red de Lousiana), no hay un sentido de solidaridad, sucede lo mismo en las redes, todo es que me das, que te doy". Así, predomina en estas redes la comunidad en el sentido de relación de intereses y se articula con la recreación de la comunidad imaginada. Entre los peruanos predomina la comunidad de identidad cultural y afectiva; tal vez un utilitarismo afectivo. Pero también de cooperación y solidaridad: recaudar fondos a favor de quien lo necesita haciendo polladas, cebichadas y asados, en los que se convive y se comparte música y bailes peruanos. En estos espacios argentinos y peruanos reproducen estructuras sociales del país de origen como sucede en otras comunidades latinoamericanas en Estados Unidos y Europa. Las redes en las que se realizan son de parentesco y amistad como la de Amalia, Alberto y Lousiana; circuitos transnacionales como la Cámara mexicano-peruano y la de los comerciantes de artesanía, y las comunidades (Comunidad peruana en la Ciudad de México y la Comunidad religiosa del Señor de los Milagros). Estas últimas tienen un sentido de compromiso social que los impulsa, pero su tendencia es a debilitarse. El Sr. García lo explica del siguiente modo:

"nos reunimos, organizamos el deporte, la participación y promovemos la relación entre peruanos sin esperar a cambio algo. Con el tiempo hemos dejado, porque también cansa, y esperamos que los nuevos que llegan hagan lo mismo, pero no es así. No sé qué tienen, que sienten, que piensan, pero no les importa la comunidad (...)”.

Tal vez el cambio generacional y su mayor heterogeneidad expliquen esta realidad, sin embargo, es posible también sea la influencia de globalización y la cultura liberal, pues tanto entre peruanos y argentinos se observa una transición entre un modelo republicano a un modelo liberal de percibir y vivir la ciudadanía, con sus particularidades en cada individuo.

\section{Redes sociales mediadas por las TIC}

Entre 1990-2009 el teléfono primero, e internet después cobran mucha importancia en las comunicaciones. José (entrevista, Perú, 2009) manifiesta sobre este hecho: "la comunicación ahora es barata, antes el teléfono era caro y nadie tenía". Martín (entrevista, Argentina, 2009) manifiesta: "la comunicación es varias veces por semana, el teléfono es barato, yo tengo una línea especial y pago muy poco, hablo varias veces por semana, además está el correo”. Germán (entrevista, Argentina, 2009) al hablar de lo mismo dice: "llamo dos o tres veces por semana, en el correo intercambiamos mensajes, archivos y el mensajero (msn) todo el tiempo. Hablamos a veces de política con los amigos, intercambiamos algunas cosas". Esta dinámica sucede con todos nuestros entrevistados y aumenta la conectividad con el 
paso del tiempo. Entre los peruanos comienza a ser fuerte a partir del 2009, mientras que entre los argentinos, internet ya es un espacio social cotidiano consolidado tiempo atrás.

De esta forma, las TIC cobran vida en la nueva configuración social de argentinos y peruanos, interconectándolos al exterior (país de destino y de origen, mundo) mediante televisión, teléfono e internet y al interior de la ciudad a través del celular y el internet. Estas interconexiones realizan en función de la actividad de cada persona y se ejecuta por el mensajero, correo electrónico y las redes sociales (facebook, twiter, hi5, entre otras).

Estas redes son a su vez el soporte electrónico y social para las comunicaciones institucionales de los dos países: Argentina y Perú. Sin embargo, la comunicación entre autoridades y ciudadanos falla o no llega oportunamente. Al respecto, Fátima (entrevista, Argentina, 2009) señala: "ellos no pueden llegar a todos los argentinos, pero al menos deben utilizar todos los espacios, como las redes, que tampoco son creados por ellos", al referirse a las deficiencias de comunicación del Consulado argentino, lo que se constata en el análisis de comunicaciones web de la Embajada y el Consultado. Las redes sociales como parte del uso más activo de los consulados sucede a partir del año 2009. El tráfico aumenta en sus secciones, aunque sigue siendo un espacio poco utilizado. Los gobiernos no hacen uso efectivo de sus páginas web ni de las redes sociales, contradiciendo el contenido de sus propias políticas de vinculación y ciudadanización. El mayor avance es del gobierno argentino.

Para los peruanos y argentinos que viven en la Ciudad de México, las redes electrónicas de los ciudadanos, a diferencia de las de sus gobiernos, son espacios en los que se recrean las relaciones y prácticas sociales que reconstituyen la identidad y el sentido de pertenencia a "comunidades imaginarias" (Anderson, 1993), de las que se sienten parte los Estados-nación. En ellas, se reproduce y produce de manera recreada las identidades nacionales y ciudadanas de origen, así como el propio Estado nación desde los ciudadanos.

Entre los peruanos estas redes son cerradas y de administración institucional o privada: 
Cuadro 4. Redes mediadas por las TIC entre los peruanos

\begin{tabular}{|c|c|c|c|}
\hline Red & $\begin{array}{l}\text { Descripción y } \\
\text { actividades }\end{array}$ & Resultados y vínculos transnacionales & $\begin{array}{l}\text { Obtención de } \\
\text { la información }\end{array}$ \\
\hline $\begin{array}{c}\text { Red del } \\
\text { Consulado } \\
\text { peruano }\end{array}$ & $\begin{array}{l}\text { Esta red opero hasta el } \\
2004 \text {, a partir de la base } \\
\text { de datos del Consulado. A } \\
\text { través de ella se hacían los } \\
\text { avisos oficiales, siendo un } \\
\text { medio efectivo de comuni- } \\
\text { cación. Desde el } 2005 \text { des- } \\
\text { apareció. Desde el } 2009 \text { se } \\
\text { ha buscado reestructurar } \\
\text { y establecer la página del } \\
\text { Consulado como espacio } \\
\text { virtual de comunicación } \\
\text { para los peruanos. Desde } \\
\text { el } 2009 \text { entre en reorgani- } \\
\text { zación y el trabajo se hizo } \\
\text { de manera coordinada en- } \\
\text { tre los miembros del Con- } \\
\text { sulado y los ciudadanos } \\
\text { del Consejo de consulta, } \\
\text { órgano creado primero } \\
\text { por decreto y luego por ley } \\
\text { para el apoyo institucional, } \\
\text { promover la ciudadanía en } \\
\text { el exterior y la integración } \\
\text { cultural y política con el } \\
\text { Perú. El soporte de comu- } \\
\text { nicación entre el Consejo } \\
\text { de Consulta y el Consula- } \\
\text { do ha sido la telefonía y el } \\
\text { correo electrónico. }\end{array}$ & $\begin{array}{l}\text { Las funciones transnacionales solamente se realizan } \\
\text { esporádicamente como actividades de asistencia en apoyo } \\
\text { al consulado, en relación a la atención de los inmigrantes } \\
\text { indocumentados, ofreciéndoles asistencia. Aunque en el } \\
\text { periodo del } 2008 \text { al } 2010 \text { prácticamente no se realizó. } \\
\text { Entre los cambios de la página web están: los integran- } \\
\text { tes del Consejo de consulta, instituciones y organizaciones, } \\
\text { páginas amarillas y los principales medios de comunicación } \\
\text { de Perú. Existía entre el } 2009 \text { y } 2010 \text {, también, informa- } \\
\text { ción sobre las actividades de interacción entre ciudadanos } \\
\text { y de estos con el Cónsul, que favorecían relaciones de ma- } \\
\text { yor proximidad. } \\
\text { La política de relación entre el } 2008 \text { y el } 2009 \text {, con el } \\
\text { nuevo Cónsul también cambió, porque se eliminaron rela- } \\
\text { ciones clientelistas y de grupos de privilegio y e3 5ipo co- } \\
\text { lonialista que lo reconocen algunos ciudadanos peruanos y } \\
\text { que lo señalan como normalizados en las relaciones con las } \\
\text { autoridades consulares y de la Embajada. } \\
\text { Inicia a su vez un proceso de politización partidaria en } \\
\text { el seno del Consejo Consultivo que afectó el trabajo coo- } \\
\text { perativo y genero disconformidades. Probablemente como } \\
\text { resultado de ese hecho no se eligió el Consejo de Consul- } \\
\text { ta en el } 2009 \text {. La autoridad consular argumentó que no } \\
\text { se cumplió los requisitos del quorum para su integración, } \\
\text { mientras que desde los ciudadanos había un sector descon- } \\
\text { tento porque se afirmaba que no había cuentas claras y no } \\
\text { se quería que el Consejo de Consulta fiscalice. En los años } \\
\text { siguientes este conflicto se agravó. }\end{array}$ & $\begin{array}{c}\text { Observación. } \\
\text { Entrevista, auto- } \\
\text { ridad consultar, } \\
2009 . \\
\text { Entrevista, Sra. } \\
\text { Nora, 2009. } \\
\text { Observación } \\
\text { participante. }\end{array}$ \\
\hline $\begin{array}{c}\text { Red dela } \\
\text { Señora } \\
\text { Nora }\end{array}$ & $\begin{array}{l}\text { Es de carácter privado, con } \\
\text { aproximadamente } 400 \\
\text { miembros y se interconec- } \\
\text { ta con otras redes meno- } \\
\text { res }^{14} \text {. Su función es infor- } \\
\text { mativa y de solidaridad. } \\
\text { El soporte era el grupo de } \\
\text { yahoo en el que se desen- } \\
\text { volvía y la comunicación } \\
\text { era vía correo electrónico } \\
\text { de los afiliados al grupo. }\end{array}$ & $\begin{array}{l}\text { En el periodo de } 2003 \text { al } 2009 \text { fue uno de los medios } \\
\text { más eficientes que los peruanos y el Consulado tenían para } \\
\text { informar de las actividades cívicas, culturales, religiosas y } \\
\text { sociales. Interconecta a la comunidad peruana en la Ciudad } \\
\text { de México, México con Lima y Chiclayo en Perú. } \\
\text { Su rol es comunitario, al respecto la Sra. Nora dice: La } \\
\text { Sra. Nora dice: "el fin de la red es para la comunidad de } \\
\text { peruanos y para la solidaridad, por eso primero se le pide } \\
\text { que envíe lo que quiere que se circule, luego si se considera } \\
\text { de interés para todos se envía, si es solamente para fines } \\
\text { lucrativos personales no se envía [...]. [...] se da a conocer } \\
\text { las comunicaciones de importancia para la comunidad del } \\
\text { gobierno peruano y autoridades que están en México." } \\
\text { Constituye un espacio transnacional en la que se es- } \\
\text { tablecen y fortalecen los vínculos culturales, identitario y } \\
\text { políticos, el más cercano al centro institucional y a la comu- } \\
\text { nidad peruana concreta en la Ciudad de México. }\end{array}$ & $\begin{array}{c}\text { Observación } \\
\text { participante. } \\
\text { Entrevista, Sra. } \\
\text { Nora. }\end{array}$ \\
\hline
\end{tabular}

Fuente: Elaboración propia

14. Existen otras redes pequeñas: la agencia de vuelos Nuevo Mundo, del Restaurante El Refugio del Inca y Andina Tours (Agencia de viaje), en las que también se generan procesos de vinculación con el país a través de su cultura y sus productos nostálgicos. 


\section{Redes sociales mediadas por la tecnología entre los argentinos}

Las redes argentinas, a diferencia de las redes sociales peruanas del Internet de carácter privadas, son públicas y abiertas a todos los argentinos y sus amigos. Son de carácter interactivo y permiten la comunicación libre de persona a persona, con fines personales, comerciales o institucionales. Entre estas redes tenemos:

Cuadro 5. Redes sociales argentinas en el internet en la que participan ciudadanos argentinos residentes en la Ciudad de México, 2008-2009

\begin{tabular}{|c|c|c|c|c|c|}
\hline Nombre de la red & Página web & Objetivo & Coordinador & Actividades/Funciones & $\begin{array}{l}\mathrm{N}^{\circ} \mathrm{de} \\
\text { Miem- } \\
\text { bros. }\end{array}$ \\
\hline $\begin{array}{l}\text { Argentina en } \\
\text { México }\end{array}$ & $\begin{array}{l}\text { http://www. } \\
\text { argenti } \\
\text { naenmexico. } \\
\text { com/in } \\
\text { dex.html }\end{array}$ & $\begin{array}{l}\text { Informar y } \\
\text { establecer nexos } \\
\text { entre } \\
\text { argentinos en } \\
\text { México y con los } \\
\text { argentinos } \\
\text { en Argentina } \\
\text { Informar sobre } \\
\text { empleo, teléfonos } \\
\text { de } \\
\text { emergencia, } \\
\text { trámites en } \\
\text { México, negocios } \\
\text { y productos } \\
\text { argentinos. }\end{array}$ & $\begin{array}{l}\text { Silvina } \\
\text { Lemes }\end{array}$ & $\begin{array}{l}\text { Información y comuni- } \\
\text { cación } \\
\text { Vinculación con Argentina } \\
\text { Profesionales y Comer- } \\
\text { ciales } \\
\text { Coordinación con el } \\
\text { Consulado }\end{array}$ & $\begin{array}{c}302 \\
183 \mathrm{H} \\
119 \mathrm{M} \\
\text { (DF) }\end{array}$ \\
\hline Despatriados & $\begin{array}{c}\text { http://www. } \\
\text { despatri } \\
\text { ados.com/paises/ } \\
\text { me } \\
\text { xico.asp }\end{array}$ & $\begin{array}{l}\text { Informar y } \\
\text { establecer nexos } \\
\text { entre } \\
\text { argentinos en } \\
\text { México y con los } \\
\text { argentinos } \\
\text { en Argentina }\end{array}$ & No se sabe & $\begin{array}{l}\text { Información y comuni- } \\
\text { cación } \\
\text { Vinculación entre argenti- } \\
\text { nos en el } \\
\text { mundo y con Argentina } \\
\text { Comercio de productos } \\
\text { nostálgicos }\end{array}$ & 211 \\
\hline $\begin{array}{c}\text { Argentinos en } \\
\text { México } \\
\text { Facebook }\end{array}$ & Facebook & $\begin{array}{l}\text { Conocer, } \\
\text { intercambiar } \\
\text { información y } \\
\text { solidaridad entre } \\
\text { argentinos que } \\
\text { radican en } \\
\text { México }\end{array}$ & $\begin{array}{c}\text { Sasa } \\
\text { Calvosa } \\
\text { Chiapas/Mo } \\
\text { nterrey }\end{array}$ & $\begin{array}{l}\text { Información y comuni- } \\
\text { cación } \\
\text { Solidaridad } \\
\text { Vinculación con Argentina } \\
\text { y otras } \\
\text { partes del mundo } \\
\text { Profesionales y comer- }\end{array}$ & 333 \\
\hline $\begin{array}{l}\text { Argentinos } \\
\text { sueltos en } \\
\text { México }\end{array}$ & & $\begin{array}{l}\text { Integrar a los } \\
\text { argentinos que } \\
\text { están en } \\
\text { México }\end{array}$ & $\begin{array}{c}\text { Gary Neder } \\
\text { Pablo } \\
\text { Gastón } \\
\text { Zappala }\end{array}$ & & 508 \\
\hline $\begin{array}{l}\text { Argentinos } \\
\text { perdidos en } \\
\text { México }\end{array}$ & & $\begin{array}{l}\text { Comunicar a los } \\
\text { argentinos en } \\
\text { México }\end{array}$ & Leo Bolzón & & 163 \\
\hline
\end{tabular}




\begin{tabular}{|c|c|c|c|c|c|}
\hline Nombre de la red & Página web & Objetivo & Coordinador & Actividades/Funciones & $\begin{array}{l}\mathrm{N}^{\circ} \mathrm{de} \\
\text { Miem- } \\
\text { bros. }\end{array}$ \\
\hline $\begin{array}{l}\text { Artículos } \\
\text { argentinos en } \\
\text { México }\end{array}$ & $\begin{array}{c}\text { Facebook } \\
\text { http://www. } \\
\text { articulo } \\
\text { sdeargentina. } \\
\text { com/ }\end{array}$ & $\begin{array}{l}\text { Comercializar } \\
\text { productos argen- } \\
\text { tinos en } \\
\text { México }\end{array}$ & $\begin{array}{l}\text { Miguel A. } \\
\text { Reale } \\
\text { Lampone }\end{array}$ & $\begin{array}{l}\text { Comerciales, Amistad, } \\
\text { profesionales }\end{array}$ & 55 \\
\hline $\begin{array}{l}\text { Argentina en } \\
\text { México }\end{array}$ & Facebook & $\begin{array}{l}\text { Dar información } \\
\text { y servicios profe- } \\
\text { sionales }\end{array}$ & $\begin{array}{c}\text { Enrique } \\
\text { Urbina Bado }\end{array}$ & \multirow{2}{*}{$\begin{array}{l}\text { Información, Comuni- } \\
\text { cación } \\
\text { Comerciales, Profesio- } \\
\text { nales }\end{array}$} & 99 \\
\hline $\begin{array}{l}\text { Argentinos en } \\
\text { México }\end{array}$ & $\mathrm{Hi} 5$ & $\begin{array}{l}\text { Compartir amis- } \\
\text { tad, información y } \\
\text { ayuda }\end{array}$ & $\begin{array}{l}\text { Alejandro } \\
\text { Pessano }\end{array}$ & & \\
\hline $\begin{array}{l}\text { Argentinos en } \\
\text { México }\end{array}$ & \multirow[t]{3}{*}{ Yahoo } & \multirow{3}{*}{$\begin{array}{l}\text { Compartir amis- } \\
\text { tad, información, } \\
\text { ayuda y produc- } \\
\text { tos nostálgicos }\end{array}$} & Víctor Pato & \multirow[t]{3}{*}{$\begin{array}{l}\text { Información, amistad, } \\
\text { Comunicación, profesio- } \\
\text { nales }\end{array}$} & \\
\hline $\begin{array}{c}\text { Argentinos en } \\
\text { DF }\end{array}$ & & & Silvina Lemes & & \\
\hline Argentos & & & Patricio Pato & & 300 \\
\hline
\end{tabular}

Fuente: Elaboración propia

En estas redes el marcador de identidad es la nacionalidad y a través de ellas, en la Ciudad de México, se ejercen derechos económicos (empleo, realización de negocios); civiles de información para la seguridad; sociales (servicios médicos, seguro médico y educación); culturales (identidad, costumbres, festividades) y derechos políticos (opinión y discusión en los foros sobre temas políticos argentinos); a través de espacios transnacionales telemáticos.

\section{Ejercicio de derechos y construcción de un espacio social-simbólico transnacional}

Los derechos se construyen y ejercen, tanto los que la ley reconoce como los que percibe y producen desde los espacios ciudadanos. Este proceso se centra lo siguiente:

En cuanto a las políticas de emigración del modelo planteado, entre argentinos y peruanos se encontraron los siguientes avances de los gobiernos:

Políticas de fortalecimiento del servicio público, se está iniciando una forma de administración bajo el enfoque del servidor público y centrado en el usuario para agilizar los trámites, implementar el servicio itinerante en las ciudades de México y el correo postal. En el caso argentino sucede lo mismo, con exclusión del servicio de correo postal.. 
Cuadro 6. Sobre la construcción de la ciudadanía

\begin{tabular}{|c|c|c|c|}
\hline Derechos & Ciudadanía Reconocida & $\begin{array}{l}\text { Ciudadanía } \\
\text { Percibida }\end{array}$ & $\begin{array}{l}\text { Ciudadanía } \\
\text { Vivida }\end{array}$ \\
\hline $\begin{array}{l}\text { Doble na- } \\
\text { cionalidad }\end{array}$ & $\begin{array}{l}\text { Perú y Argentina reconocen el de- } \\
\text { recho a la doble nacionalidad. } \\
\text { México exige renuncia de naciona- } \\
\text { lidad a peruanos y argentinos. } \\
\text { Naturalización como medio para } \\
\text { tener doble ciudadanía. }\end{array}$ & $\begin{array}{l}\text { Los peruanos y argentinos perci- } \\
\text { ben como injusticia que México no } \\
\text { reconozca la doble nacionalidad. } \\
\text { La mayoría de los entrevistados } \\
\text { (as) no se naturalizaron porque } \\
\text { sus lealtades a su país de origen. } \\
\text { Consideran un doble discurso } \\
\text { del gobierno mexicano que exige } \\
\text { derechos para los mexicanos en } \\
\text { Estados Unidos que no se otorga } \\
\text { a los inmigrantes en México. }\end{array}$ & $\begin{array}{l}\text { Tres peruanos y dos (de los veinte } \\
\text { entrevistados) argentinos se na- } \\
\text { turalizaron y ejercen derechos en } \\
\text { los dos Estados. } \\
\text { Informalmente peruanos y argen- } \\
\text { tinos participan en organizaciones } \\
\text { sociales o políticas, en marchas } \\
\text { y protestas que los consideran } \\
\text { justas. }\end{array}$ \\
\hline $\begin{array}{l}\text { Derecho al } \\
\text { voto. }\end{array}$ & $\begin{array}{l}\text { Argentina y Perú reconocen el } \\
\text { derecho al voto de los peruanos y } \\
\text { argentinos para elecciones presi- } \\
\text { denciales y parlamentarias. } \\
\text { México no permite el voto de los } \\
\text { inmigrados ni en elecciones loca- } \\
\text { les ni presidenciales. }\end{array}$ & $\begin{array}{l}\text { Los peruanos y argentinos perci- } \\
\text { ben que ellos deben elegir a sus } \\
\text { representantes al menos en la } \\
\text { Ciudad de México donde viven. } \\
\text { Sustentan su que ellos pagan im- } \\
\text { puestos igual y a veces más que } \\
\text { los nacionales y no se les debe ne- } \\
\text { gar sus derechos políticos. }\end{array}$ & $\begin{array}{l}\text { Los naturalizados ejercen al voto } \\
\text { en los dos Estados. }\end{array}$ \\
\hline $\begin{array}{l}\text { Derechos } \\
\text { de opinión } \\
\text { y reunión }\end{array}$ & $\begin{array}{l}\text { La constitución mexicana prohíbe } \\
\text { opinar o participar en asuntos pú- } \\
\text { blicos relacionados a México, bajo } \\
\text { posibilidad de ser expulsado sin } \\
\text { previo juicio del país }\end{array}$ & $\begin{array}{l}\text { Peruanos y argentinos consideran } \\
\text { que no es democrático porque } \\
\text { están como amordazados. Asi- } \\
\text { mismo, argumentan que los mexi- } \\
\text { canos documentados en Estados } \\
\text { Unidos no tienen tales restriccio- } \\
\text { nes, por lo que el gobierno mexi- } \\
\text { cano debe ser más incluyente. Sin } \\
\text { embargo, agregan, que respetan } \\
\text { las leyes y disposiciones del país. }\end{array}$ & $\begin{array}{l}\text { Los argentinos entre } 1975 \text { a } 1983 \\
\text { tuvieron muchas organizaciones } \\
\text { políticas que luchaban en contra la } \\
\text { dictadura y contaban con el apoyo } \\
\text { del gobierno mexicano. La ciudad } \\
\text { de México era un espacio transna- } \\
\text { cional para ejercer sus derechos } \\
\text { políticos con respecto a Argentina } \\
\text { fuera de su país. } \\
\text { Los peruanos tenías actividades } \\
\text { políticas partidarias en México, } \\
\text { tanto de partidos de izquierda } \\
\text { como del Partido Aprista Perua- } \\
\text { no, que se disolvieron después de } \\
1990 \text {. No existen organizaciones } \\
\text { políticas ni activismo político des- } \\
\text { pués de } 1990 \text {. Estos temas solo } \\
\text { lo tratan en sus redes de amigos } \\
\text { mexicanos y connacionales. }\end{array}$ \\
\hline $\begin{array}{l}\text { Derechoa } \\
\text { protestar }\end{array}$ & $\begin{array}{l}\text { Todos los documentados ejercen } \\
\text { derecho al trabajo pero si no están } \\
\text { naturalizados no pueden buscar } \\
\text { libremente un trabajo porque es- } \\
\text { tán condicionados por el estatus } \\
\text { migratorio. Los indocumentados } \\
\text { no pueden trabajar legalmente. } \\
\text { Pueden ejercer todo tipo de acti- } \\
\text { vidad económica siempre y cuan- } \\
\text { do tengan el permiso para hacerlo. }\end{array}$ & $\begin{array}{l}\text { Consideran que están en des- } \\
\text { ventaja para la movilidad social y } \\
\text { buscar un mejor trabajo, porque } \\
\text { si van a las empresas estas les } \\
\text { piden el permiso para trabajar en } \\
\text { dicha actividad y si van al Instituto } \\
\text { Nacional Electoral (INE) les piden } \\
\text { una carta de una empresa. Así se } \\
\text { "echan la pelota uno a otro", seña- } \\
\text { lan. } \\
\text { Perciben que las redes sociales y } \\
\text { de amigos, mayormente mexica- } \\
\text { nos facilitan el acceso al trabajo y } \\
\text { otros derechos. }\end{array}$ & $\begin{array}{l}\text { Trabajan casi todos los entrevista- } \\
\text { dos en otros trabajos además del } \\
\text { que están autorizados informal- } \\
\text { mente. Incluso los indocumenta- } \\
\text { dos, aunque manifiestan que son } \\
\text { sometidos a abusos, no pago y sa- } \\
\text { larios muy reducidos, y sin acceso } \\
\text { a derechos sociales. El Estado, en } \\
\text { este caso, condiciona legalmente } \\
\text { las vivencias de subempleo, des- } \\
\text { empleo y exploración. } \\
\text { Las redes sociales directas y de in- } \\
\text { ternet habilitan una extensión de } \\
\text { hecho de ofertas de trabajo en el } \\
\text { caso de los argentinos que viven } \\
\text { en Argentina. }\end{array}$ \\
\hline
\end{tabular}




\begin{tabular}{|c|c|c|c|}
\hline Derechos & Ciudadanía Reconocida & $\begin{array}{c}\text { Ciudadanía } \\
\text { Percibida }\end{array}$ & $\begin{array}{c}\text { Ciudadanía } \\
\text { Vivida }\end{array}$ \\
\hline $\begin{array}{l}\text { Derechos } \\
\text { culturales }\end{array}$ & $\begin{array}{l}\text { El gobierno de la Ciudad en este } \\
\text { caso impulsa desde el } 2008 \text { pro- } \\
\text { gramas interculturales y de inclu- } \\
\text { sión de los inmigrantes extranje- } \\
\text { ros, que actualmente ya tiene su } \\
\text { propia ley propia para favorecer el } \\
\text { ejercicio de sus derechos. Al reali- } \\
\text { zar este estudio, era un proyecto } \\
\text { de ley. La ley de Población que re- } \\
\text { gía entonces no favorecía mucho } \\
\text { estos derechos. }\end{array}$ & $\begin{array}{l}\text { Culturalmente se sienten parte } \\
\text { de la comunidad latinoamerica- } \\
\text { na, otros del mundo, otros de la } \\
\text { Ciudad de México y de su país, } \\
\text { mientras que un argentino y una } \\
\text { peruana se sentían culturalmente } \\
\text { vinculados a su localidad de origen } \\
\text { en Argentina y Perú. }\end{array}$ & $\begin{array}{l}\text { Ejercen todos sus derechos, hasta } \\
\text { su identidad. La ciudad, como dice } \\
\text { Borja, le permite producir y vivir } \\
\text { derechos, incluso el derecho a la } \\
\text { ilegalidad. } \\
\text { Los inmigrantes peruanos y ar- } \\
\text { gentinos de acuerdo a su propia } \\
\text { experiencia ejercen sus derechos } \\
\text { culturales directamente y a través } \\
\text { de las TIC. }\end{array}$ \\
\hline $\begin{array}{l}\text { Derechos } \\
\text { sociales }\end{array}$ & $\begin{array}{l}\text { El gobierno peruano tiene pro- } \\
\text { gramas destinados a la asistencia } \\
\text { en caso de emergencia, pobreza o } \\
\text { desastre; promover la educación } \\
\text { para sus emigrantes y promueve } \\
\text { programas de vivienda. El argen- } \\
\text { tino también tiene disposiciones } \\
\text { legales para la asistencia, pero en } \\
\text { el caso de México los inmigrantes } \\
\text { señalan que eso queda solamente } \\
\text { en la norma escrita. }\end{array}$ & $\begin{array}{l}\text { Los peruanos perciben que el } \\
\text { consulado no maneja trasparen- } \\
\text { temente esos fondos y que no se } \\
\text { sabe si realmente se utilizan. } \\
\text { En el transcurso del periodo de } \\
\text { estudios, Nora, que está desde } \\
\text { los setentas en México, señala } \\
\text { que en la mayoría de cónsules no } \\
\text { cumplen dicha función y que so- } \\
\text { lamente uno entre } 1970 \text { al } 2009 \\
\text { había usado apropiadamente esos } \\
\text { fondos y había ayudado mucho } \\
\text { a los emigrados sobre todo a los } \\
\text { indocumentados. }\end{array}$ & $\begin{array}{l}\text { Asistencia y apoyo a los indocu- } \\
\text { mentados, aunque entre el } 2008 \\
\text { al } 2009 \text { estuvo ausente este de- } \\
\text { recho que tienen los peruanos con } \\
\text { necesidad. } \\
\text { En el periodo 2005-2008, se dejó } \\
\text { morir sola a una estudiante perua- } \\
\text { na, por la negativa de quien dirigía } \\
\text { el consulado de viajar hasta el Es- } \\
\text { tado donde estaba la joven a cum- } \\
\text { plir con su deber de asistencia. Se } \\
\text { asistió solamente cuando ya falle- } \\
\text { ció con el apoyo a la repatriación } \\
\text { del cadáver. }\end{array}$ \\
\hline $\begin{array}{l}\text { Construc- } \\
\text { ción de } \\
\text { un espacio } \\
\text { social } \\
\text { simbólico } \\
\text { nacional }\end{array}$ & $\begin{array}{l}\text { Se desarrolló en el Perú un con- } \\
\text { junto de programas bajo la cons- } \\
\text { trucción Quinto suyo y en Argen- } \\
\text { tina el Programa Provincia } 25 .\end{array}$ & $\begin{array}{l}\text { Algunos peruanos se sienten } \\
\text { parte del Quinto suyo (El imperio } \\
\text { de los incas se dividía en cuatro } \\
\text { suyos). El término alude a un te- } \\
\text { rritorio más, evocando al imperio } \\
\text { incaico, el cual sería el resto del } \\
\text { mundo y conformado por todos } \\
\text { los peruanos que viven en el ex- } \\
\text { tranjero. }\end{array}$ & $\begin{array}{l}\text { Es promovido desde el Estado y } \\
\text { lo promueven ciertos sectores } \\
\text { sociales emigrantes, como ele- } \\
\text { mento de pertenencia, identidad } \\
\text { y vinculación simbólica con su país } \\
\text { de origen. }\end{array}$ \\
\hline Integración & $\begin{array}{l}\text { Existen políticas diversas para la } \\
\text { emigración y vinculación de los } \\
\text { emigrantes tanto en Argentina } \\
\text { como en Perú. Son ausentes en } \\
\text { México, respecto a la federación, } \\
\text { pero se contaba y cuenta en el } \\
\text { Distrito si. }\end{array}$ & $\begin{array}{l}\text { Los peruanos y argentinos de- } \\
\text { sean integrarse legalmente pero } \\
\text { desean no se les pida renunciar a } \\
\text { su nacionalidad. Asimismo, creen } \\
\text { que se les debe permitir votar al } \\
\text { menos en la ciudad. }\end{array}$ & $\begin{array}{l}\text { Se sienten ciudadanos de la Ciu- } \\
\text { dad de México la mayoría, algunos } \\
\text { también de México como país, } \\
\text { pero estos últimos son los que vi- } \\
\text { ven más de diez años en México o } \\
\text { están naturalizados. }\end{array}$ \\
\hline
\end{tabular}

Fuente: Elaboración propia con base en las entrevistas y datos de la observación participante

Políticas de asistencia, realizados en caso de emergencia para suplir las necesidades básicas de alimentación, salud, seguridad, apoyo legal y repatriación en casos de emergencia. En el Perú cuenta con un presupuesto especial y es cuestionado por algunos ciudadanos porque no se tienen información de su uso. En el caso de Argentina es menos eficiente y cuando se han presentado casos, no ha respondido eficazmente y gestiona ayuda de asociaciones argentinas y personalidades para ofrecer el apoyo. Fátima, señala: “no existe apoyo real”. Aún en este caso son débiles las políticas los estados argentino y peruano. 
Políticas de vinculación. En el caso las políticas de retorno que existen desde los setentas y van por una tercera fase, en la que se desarrolla El programa Red de Argentinos Investigadores y Científicos en el Exterior, más conocido como RA@Í́CES, una experiencia trasnsnacional promovida desde el gobierno, que involucra redes virtuales de investigadores, seminarios y talleres para promover la transferencia de conocimientos entre argentinos residentes en el exterior con los nacionales y promueve acuerdos con empresas en Argentina fomentar el empleo para argentinos altamente capacitados que se encuentran en el exterior (García, 2008, p. 114-115). En esta red, se constató que participó un investigador que viven en México. Entre los peruanos estas políticas de retorno son recientes.

Políticas de ciudadanización, son eminentemente de carácter político. El gobierno peruano, a través del programa para promover la ciudadanía en el exterior y los Consejos de consulta, busca la integración cultural y política de los peruanos con el Estado peruano, la integración de las comunidades en el exterior y la participación política a través del sufragio, la defensa de sus derechos en el país de destino y la participación política en el país de destino en los límites que la ley lo permita. En este sentido, tres Consejos de consulta existieron entre el 2003 y el 2009, mismo que se ha involucrado en la reestructura institucional del Consulado y en la atención a los inmigrantes peruanos retenidos en la estación migratoria de Iztapalapa.

El gobierno argentino creó el "Programa Provincia 25" por Resolución 452/2007 del Ministerio del Interior y para atender los intereses de los ciudadanos. Sus líneas de acción son: 1) participación ciudadana (sufragio y derecho de representación), 2) gestión de documentación, 3) derechos sociales y 4) comunicación e información. Concretamente, busca promover un sistema de comunicación permanente, eficaz y que se constituya en soporte para la toma de decisiones y la atención de los derechos sociales de los emigrados (Follonier et al, Ministerio del Interior: 2005). Similar a los Consejos de Consulta del Perú se promueve la formación de los Institutos Ciudadanos, cuyo objetivo es integrar a la comunidad argentina en el exterior, asistirlas en las gestiones públicas y fortalecer los vínculos de éstos y el Estado (Resolución 452/2007), pero que aún no se concreta. Este programa es desconocido por los argentinos en México, lo que muestra la falla comunicacional del gobierno y el escaso interés de los ciudadanos de explorar las políticas y programas para los emigrados.

No se percibe aún impacto de estas políticas en la ciudadanía peruana y argentina que viven en México, a excepción del programa RA@ícES y los Consejos de Consulta. Sin embargo, como resultado de la migración y el uso de las TIC se evidencia que:

1) Los derechos económicos extiende las opciones de trabajo en el caso de los argentinos que viven en Argentina, no así entre los peruanos por la debilidad de sus redes transnacionales. 
2) En los países, las redes sociales reducen los costos y riesgos de desplazamiento, como lo señala en sus estudios, porque facilitan los contactos que proporcionan información, hospedaje y apoyo solidario, aunque es menos frecuente entre los argentinos y más entre peruanos.

3) Las redes mediadas por las tecnologías provee información sobre los negocios étnicos, trabajo, servicios profesionales, de trámites y otras, como información de recetas de comida, música, deportes, política e información y comunicación con el gobierno.

4. Las redes disminuyen los impactos jurídicos, económicos e institucionales negativos de la migración a México y suplen parcialmente las necesidades resultantes de la inmigración frente al abandono administrativo y los vacíos de información estatal de los consulados y las embajadas, Problemas éstos, que las políticas de emigración buscan eliminar pero que todavía no concretan en logros y es cuestionado por los inmigrantes (Entrevistas, 2009).

5) Los derechos culturales son vividos plenamente (entrevistas, 2009; observación participante; análisis de contenidos web), desde la reproducción simbólica en restaurantes y casas, retratando sus símbolos identitarios ${ }^{15} \mathrm{y}$ en internet (cultura, la música, los bailes, equipos de futbol, personajes históricos, deportivos y de la farándula y la comida, paisajes), hasta como elementos de identidad cultural y nacional, consumo cultural y reconstrucción simbólica, cuya influencia es mayor que la de los símbolos patrios (bandera, himno nacional). El internet es el medio que se constituye en central para estos procesos de reproducción y construcción cultural e identitaria, que se realiza en contacto con diversas culturas de origen, de destino y del mundo, al ejercer sus derechos culturales y realizar estrategias mediáticas. Es tan importante, que una característica que aparece entre peruanos y argentinos es que conocen mejor la pluralidad de su país de origen, se vuelven más tolerantes y adoptan una perspectiva menos etnocéntrica, más abierta a las diferencias, más abierta e incluyente de la ciudadanía.

6. Los derechos políticos se incorporan a la vida en la red: información, noticias y comunicación con un amigo o familiar con quien hablan sobre temas políticos, se articulan a la ciudad. Un dato interesante es: hablan de política con el padre o un amigo (hombres), aún las mujeres; lo que muestra las estructuras patriarcales que relacionan al hombre con lo público. El corolario, es la significatividad que comienza a tener la participación política a distancia, particularmente en las campañas electorales, que en el caso de los peruanos en el 2011 fue muy activa.

15. Ejemplos de esto, son Machu Pichu, el equipo de fútbol de la época de auge, la música criolla y andina, entre los peruanos; y entre Argentina: paisajes de Buenos Aires o de los pueblos de origen, equipos de fútbol, Gardel, Maradona, forman parte de los espacios de encuentro o de domicilios. Además, las fiestas y encuentros, el simple hecho del habla y los códigos sociales al comunicarse son para ellos, como afirman, "sentirse que pertenecen a un lugar", "que se encuentran con los suyos", que "vuelven a su identidad" 
7. Fortalecimiento de la identidad y ciudadanía nacional, como resultado de la migración y la integración de las TIC como medio de enlace con sus países de origen y sus connacionales.

8. Fortalecimiento de las redes directas a partir de las redes digitales, formando b-redes activas de peruanos y argentinos en la ciudad. (Observación, 2009; Análisis documental, 2009-2012).

\section{Conclusiones}

Las redes sociales directas y mediadas por la tecnología son espacios en los que se realiza el transnacionalismo y en el cual se construye una ciudadanía transnacional, cuyas características depende de cada coyuntura. Así, entre 1970-1989, entre los argentinos fue de fuerte activismo político transnacional desde los inmigrantes, pero en redes directas. Desde 1990 se centra en los derechos económicos y sociales se realizan en torno al internet y b-redes. Entre los peruanos, en los dos periodos el ejercicio predominante es de los derechos económicos y culturales, con la implementación exitosa del voto en el exterior, situación que sigue igual. En el segundo periodo, a partir del 2009, cobra central importancia el espacio de los flujos, donde también se generan espacios transnacionales.

Las redes digitales como las directas cumplen las siguientes funciones: 1) integración entre inmigrantes, familiares, amigos y profesionales, con su país de origen, de destino y el mundo; 2) la formación de un espacio transnacional en red en el que se interconectan colectividades de origen y destino, donde circulan bienes e información social, cultural, económica y política, cuyo eje principal es la nacionalidad, la amistad y la familia; 3) construcción de b-redes (redes mixtas digitales-directas); 4) formación de comunidades concretas en términos de asociación de intereses o de confianza (Tönnies, 1879) articuladas con las comunidades imaginadas de peruanos y argentinos, así en prácticas de nacionalismo banal se reproduce la comunidad imaginada nacional (Feliú y Peñaranda, 2012); y 5) reproducción, fortalecimiento y reconfiguración de la identidad y ciudadanía nacionales y del Estando nación, desde los emigrantes y sus redes directas y mediadas por las TIC.

Como consecuencia, emergen identidades y ciudadanía transnacionales de los siguientes tipos: a) en relación con el Estado de origen más allá del territorio, b) en relación al Estado de origen y de destino al adoptar la ciudadanía de la Ciudad de México, c) una ciudadanía supranacional a través de internet, latinoamericana y universal, como encuentra Besserer (1999) con comunidades mexicanas de emigrantes. A su vez, la integración ciudadana se da a partir de la condición concreta de cada inmigrante y se realiza en torno cuatro espacios: país de origen, la Ciudad de México, América Latina y el mundo, lo que es posible por la existencia de los espacios digitales. De este modo, la ciudadanía nos vuelve, histórica y paradójicamente, al 
encuentro entre ciudadanía de la ciudad, nacional y cosmopolita, confluencia en la cual la ciudad es el nodo de una red de redes digitales y directas, en la que se reproduce y reconstruye la ciudadanía y diversas identidades.

El internet y sus redes sociales; la telefonía (fija y móvil) y la televisión satelital, permiten la creación de espacios transnacionales de nación a nación y supranacionales en los que construyen y ejercen derechos económicos, sociales, civiles, culturales y políticos. En este espacio nace la ciudadanía digital transnacional. Esta ciudadanía se desarrolla en tres dimensiones: espacios mediáticos en el que se realizan la cultura, los símbolos ciudadanos y la identidad ciudadana en un campo mediático de la televisión y el internet de país a país; en redes sociales, en el que se ejercen derechos y construyen compromisos cívicos; y en espacios suprnacionales en donde se configura una identidad latinoamericana y cosmopolita.

Estos espacios digitales y los espacios de lugares, transnacionales, generan y fortalecen la cohesión social y sentimiento de comunidad, en los que se comienza a configurar una ciudadanía intercultural, transnacional y digital. El espacio virtual también favorece la identificación simbólica de integración que se promueve desde el Estado para internalizar en los emigrantes su pertenencia nacional mediante el llamado Quinto Suyo en Perú (Berg y Tamagno, 2004) y Provincia 25 en Argentina (Follonier et al, 2005). Internet se convierte en un medio importante para su construcción, así entre los peruanos en el facebok existen varias páginas y grupos con el nombre de Quinto Suyo, en los que participan peruanos que viven en la Ciudad de México. De este modo,en estos espacios telemáticos se fortalece el componente identitario-simbólico, que se expresa en cada peruano y argentino de manera diferente, a partir de su propia experiencia de inmigrante, donde el tiempo de vivir en México (más de cinco años), adquirir la nacionalidad mexicana, tener hijos mexicanos y el trabajo se convierten en fuentes de integración a la ciudad, pero sin perder la identidad de origen.

\section{Referencias}

Álvarez G., J. 1. (1998). Cómo hacer investigación cualitativa. México: Paidós.

Appadurai, A. (1999). Soberanía sin territorialidad: Notas para una geografía postnacional. Revista Nueva Sociedad, (163), 38-64.

Anderson, B. (1993). Comunidades Imaginadas. México D. F.: Fondo de Cultura Económica.

Basch, L., Glick N. Schiller y C. Szanton Blanc. (1994). Nations Unbound: Transnational Projects, Postcolonial Predicaments, and Deterritorialized NationStates. Pa: Gordon y Breach Langhorne. 
Bauböck, R. (1991). Migration and Citizenship. New Community, 1(18), 27-48.

Bauböck, R. (2003). Towards a political theory of migrant transnationalism. International Migration Review, 37(3), 700-723.

Basch, L., Glick N. y Szanton-Blanc, C. (1994). Nations Unbound: Transnational Projects, Postcolonial Predicaments, and Deterritorialized Nation-States. Langhorne, Pa.: Gordon y Breach

Brubaker, R. (1998) 'Immigration, Citizenship, and the Nation-State'. Shafir, G. (Ed.). The Citizenship Debates. Minneapolis: University of Minnesota Press.

Calderón, L. (Edit.). (2003b). Votar a la distancia: la extensión de los derechos políticos a migrantes: experiencias comparadas. México: Instituto Mora/Consejo Superior de Investigaciones Científicas.

Castles, S. y Davidson, A. (2000). Citizenship and Migration, Globalization and the politics of blonging. New York: Routledge.

Cerruti, M. (2005). La migración peruana en la Ciudad de Buenos Aires: Su evolución y características. Red de Revistas Científicas de América Latina y el Caribe, España y Portugal, Buenos Aires, Año 2, Vol. 2, (2), 7-28.

Cortina, A. 2003. (1997). Ciudadanos del mundo. Hacia una teoría de la ciudadanía. Barcelona: Alianza Editorial.

Berg Dalum, U. y C. Tamagno. (2004). El Quinto Suyo: conceptualizando la "diáspora peruana” desde abajo y desde arriba. Lima: CEPROM/New York University, $1-31$.

Besserer, F. (1999). Estudios transnacionales y ciudadanía transnacional. G. Mummert (Edit.) Fronteras Fragmentadas. Colegio de Michoacán-CIDEM, México, 215-238.

Bilbeny, N. (2004). Ética Intercultural: de la Razón Práctica a los retos de la diversidad cultural. Barcelona: Ariel.

Bilbeny, N. (2002). Por una causa común. Ética para la diversidad, Barcelona: Editorial Gedisa.

Borja, J. (2000). Ciudad y ciudadanía. Dos notas. Geògraf urbà. WP, 177, Barcelona: Institut de Ciències Polítiques i Socials.

Calvelo, L. (2008). La emigración de argentinos entre 1960 y 2002. Mimeo.

Castells, M. (1997). La sociedad red. La era de la información. Vol. I. Madrid: Alianza Editorial. 
Congreso de la República. (2004). Ley No 28182. Ley de incentivos migratorios. Febrero.

Cooley, Ch., (2003). Social organization: A study of the larger mind. New York: Charles Scribner's Sons.

Diario Oficial El Peruano. (2010). Ley No. 29495. Ley de Consulta de las Comunidades peruanas en el exterior. Lima: DOP.

Diario Oficial El Peruano. (2010). Reglamento de la Ley 29495. Reglamento de ley de los consejos de consulta de las comunidades peruanas en el exterior. Lima: DOP.

Diario Oficial de la Federación. (2009). Constitución política de México. Última reforma publicada. México D. F.: Cámara de diputados del H. Congreso de la Unión/Secretaría General de Servicios Parlamentarios/Centro de Documentación, Información y Análisis.

Escrivá, Á. (2000). Empleadas de por vida, Peruanas en el servicio doméstico de Barcelona. Papers, 60, pp. 327-342.

Enríquez, R. (2000). Redes sociales y pobreza: mitos y realidades. La ventana, Revista de estudios de género, (11), Guadalajara: Universidad de Guadalajara.

Feliú, J., Peñaranda, M. y Adriana G. J. (2012). Comunidades imaginadas. Nacionalismo banal en los locutorios de Barcelona. Revista de Antropología Iberoamericana, 7(2), 192-224.

Fernández T., J. (2010). Migración internacional, ciudadanía e integración: percepciones, derechos y prácticas ciudadanas de los peruanos y argentinos en la Ciudad de México, 1970-2009. (Tesis de Doctorado, inédita). Ciencias Sociales con especialidad en Estudios Regionales. Tijuana, México: El Colegio de la Frontera Norte, A.C.

Follonier et al. (2005). Programa Provincia 25. Buenos Aires: Ministerio del Interior, 1-25.

Gamlen, A. (2006). Diaspora Engagement Policies: What are they, and what kind of states use them?. Working Paper, 32, Compas, University of Oxford.

Gamlen, A., Cummings, P. y Vaaler y Laura Rossouw. (2013). Explaining the Rise of Diaspora Institutions. Working Papers, Paper 78. Oxford: University of Oxford.

García de Fanelli, A. (2008). Políticas Públicas frente a la fuga de cerebros: reflexiones a partir del caso argentino. Revista de la Educación Superior, (4), 111-121. 
Garzón G, L. (2006). Trayectorias de integración de la inmigración argentina y ecuatoriana en Barcelona y Milano. Tesis de Doctorado. Barcelona: Universidad Autónoma de Barcelona.

Glick, N. y Fouron, G., (2001) Woke Up Laughing: Long-Distance Nationalism and the Search for Home, Durham, N.C.: Duke University Press.

Gogo, D. y Dutra, 1. (2009). Latinoamericanos en el sur de Brasil: recepción mediática y ciudadanía de las migraciones transnacionales. Comunicación y Sociedad, (11), 135-162.

González-Rábago, Y. (2012). Migración transnacional colombiana y estrategias políticas online. reproducción de la comunidad a través de la vinculación transnacional. Anfora, 19 (32), 69-90.

Goldring, L. (2007). Movilidad, ciudadanía y nuevas formas de participación política. Ibarra Mateos, M. (Coord.). Migración y reconfiguración transnacional flujos de población, Puebla: Universidad Iberoamericana de Puebla, 145-153.

Gobierno de la República del Perú. (2005). Reglamento de la ley No 28182.

Decreto Supremo $N^{o}$ 028-2005-EF. Lima: Gobierno de la República del Perú.

Held, D. (1997). Ciudadanía y autonomía. La Política, 3.

Hiernaux, D. y M. Zárate (Eds.) (2008). Espacios y transnacionalismo. México: Universidad Autónoma Metropolitana-Unidad Iztapalapa.

Innerarity, D. (2006). El nuevo espacio público. Madrid: Espasa-Calpe.

Kymlicka, W. (2003). La política vernácula. Nacionalismo, multiculturalismo y ciudadanía. Barcelona: Paidós.

Kymlicka, W. 1996. Ciudadanía Multicultural: una teoría liberal de los derechos de las minorías. Barcelona: Paidós.

Labrador, J. (2001). Identidad e Inmigración. Un estudio cuantitativo con inmigrantes peruanos en Madrid. Madrid: Universidad Pontificia de Comillas.

Lafleur, J. (2013). Why do states enfranchise citizens abroad? Comparative insights from Mexico, Italy and Belgium. Global Networks, 11(4), 481-501. doi:10.1111/j.1471-0374.2011.00332.x

Levitt, P. y De la Dehesa, R. (2003). Transnational Migration and the Redefinition of the State: Variations and Explanations, Ethnic and Racial Studies, 26(4), pp. 587-561.

López S., A, M. (2002). Los retos de la inmigración. Isegoría, (26), 85-105.

Luque Brazán, J. C. (2002). Los caminos de la ciudadanía. Del modelo nacional al 
modelo postnacional. El caso de los inmigrantes peruanos en Santiago de Chile. Tesis de maestría, Facultad Latinoamericana de Ciencias Sociales. México: UNAM.

Novick, S. (1996). Políticas de Población Argentina, Análisis Comparativo entre el Régimen Militar (1976-1983) y la democracia (1984-1994), Welti, C. Dinámica Demográfica y Cambio Social, XX Congreso de la Asociación Latinoamericana de Sociología, México: FNUAP.

Novick, S. et al. (2007). Sur-norte. Estudios sobre la emigración reciente de argentinos. Buenos Aires: Universidad de Buenos Aires/Instituto de Investigaciones Gino Germani.

Marshall, T. H. y Thomas B. (1998). Ciudadanía y clase social. Madrid: Alianza Editorial.

Miller, D. (1997), Sobre la nacionalidad: Autodeterminación y pluralismo cultural. Barcelona: Alianza Editorial.

Ministerio del Interior. (2007). Programa Provincia 25. Resolución 452/2007. Buenos Aires: MI.

Ministerio de Relaciones Exteriores. (2005). Reglamento consular. Decreto Supremo $N^{o}$ 076-2005-RE. 5 de octubre del 2005. Lima: MRE.

Ministerio de Relaciones Exteriores. (2003). Decreto Supremo No. 108-2003-RE. Lima: MRE.

Ministerio de Relaciones Exteriores. (2003). Res. Ministerial No.272-RE-2003. Lima. MRE.

Moraes, N. (2008). La nación más allá del territorio nacional. Nacionalismo a distancia de migrantes uruguayos en España. Gazeta De Antropología, 24(1), Artículo 06.

Padilla, B. (2011). Engagement policies and practices: Expanding the citizenship of the brazilian diaspora. International Migration, 49(3), 10-27.

Padilla, B., \& Ortíz, A. (2012). Ciudadanía transnacional de latinoamericanos en Portugal: Considerando el país de origen y de destino. Revista De Estudos E Pesquisas Sobre as Américas, 6(1), 1-18.

Pajares, M. (2005). La integración ciudadana: una perspectiva para la inmigración. Barcelona: Icaria.

Peñaranda, D. et al (2011). El acceso público a las tecnologías de la información y la comunicación: el lugar de los locutorios en los procesos migratorios. Vol. 2011/1 (70), Papeles del CEIC, 1-37. 
Peñaranda, D. (2011). Migrando en tiempos de globalización: usos de tecnologías de la información y la comunicación en contextos migratorios transnacionales. F.J. García y N. Kressova (Coord.) Actas del Congreso Internacional sobre Migraciones en Andalucía, 2023-2032. Granada: Instituto de Migraciones.

Pérez, N. (2009). Las políticas migratorias como fuente de ciudadanía en el MERCOSUR. Población. Buenos Aires: Dirección Nacional de Población/ Ministerio del Interior, 43-47.

Pérez, L. (1991). Reflexiones sobre el estudio de la identidad étnica y la identidad nacional. Warman A. y Argueta A. Nuevos enfoques para el estudio de las etnias indígenas en México. México: UAM-CIIH: 317-367.

Pries, L. (1999): Migration and Trasnational Social Spaces. Sidney: Ashsgate.

Ramírez G., J. (2013). La política Migratoria en Ecuador. Ruptura, tensiones, continuidades y desafíos. Quito: Cuadernos Universitarios.

Retis, J. (2011). La condición transnacional de las prácticas comunicativas y los retos de la ciudadanía cultural: Latinoamericanos en contextos diaspóricos. California: University Northridge.

Riesco, A. (2003). Enclaves y economías étnicas desde la perspectiva de las relaciones salariales”, en los Cuadernos de relaciones laborales, 21(2), 103-125.

Schuk, Peter H. (1998). Plural Citizenships. en Pickus J., y M. Noah. Immigration and Citizenship in the Twenty-First Century (pp. 149-191). Oxford, Rowman,

Stake, R. (1998). Investigación con estudios de casos. Madrid: Morata.

Smith, R. (1995). Los ausentes siempre presentes: The Imagining, Making, and Politics of a Transnational Community Between New York and Ticuani, Puebla. Tesis de Doctorado, Columbia: Columbia University,

Smith, R. C. (1999). Reflexiones sobre migración, el estado y la construcción, durabilidad y novedad de la vida transnacional. Mummert, G. (Ed). Fronteras fragmentadas. México: El Colegio de Michoacán.

Solanes Corella, A. (2008). La participación política de las personas inmigrantes: cuestiones para el debate. En Derechos y libertades, (18), Época II, 67-95.

Stefoni, C. (2004). Inmigración y Ciudadanía: La formación de comunidades peruanas en Santiago y la emergencia de Nuevos Ciudadanos. Política, (043), Santiago, Universidad de Chile, pp. 319-336.

Taylor, (C). 1993, El multiculturalismo y la política del reconocimiento. México D. F.: Fondo de Cultura Económica. 
Taylor, Ch. (1997). ¿Qué principio de identidad colectiva?, La Política, (3).

Taylor, S. y Bogdan, R. (1992). Introducción a los métodos cualitativos de investigación. Barcelona: Paidós.

Tönnies, F. (1979) Comunidad y Sociedad. Barcelona: Península.

Turner, B. (1993), Cytizenship and Social theory. London: Sage Publications.

Vono de Vilhena, D. (2006). Vinculación de los Emigrados Latinoamericanos y Caribeños con su País de Origen: Transnacionalismo y Políticas Públicas. Serie Población y Desarrollo. Santiado de Chile: CELADE/División de Población de la CEPAL

Velazco, J. (1998). La migración laboral internacional como estrategia familiar: el caso de los peruanos en Italia, 1-25.

Yankelevich, P. (2004). México, País Refugio. La experiencia de los exilios en el siglo $X X$. México: INAH y Plaza Valdés.

Yankelevich, P. y Jensen, S. (Cords.). (2007). Exilios. Destinos y experiencias bajo la dictadura militar. Buenos Aires: Libros del Zorzal. 